\title{
تنظيم النسل: مفاهيمه التطبيقية دراسة مقاصدية
}

Ahmed El-Mogtaba Bannga Ahmed Ali

Kulliyyah of Islamic Revealed Knowledge and Human Sciences, International Islamic University Malaysia, Kuala Lumpur.

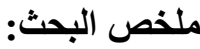

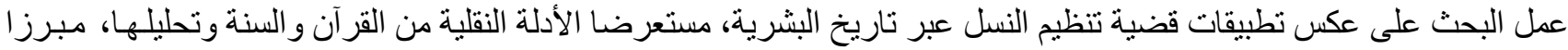

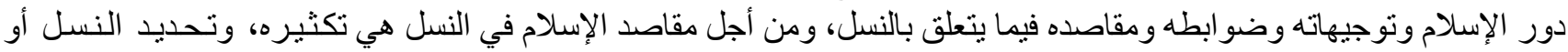

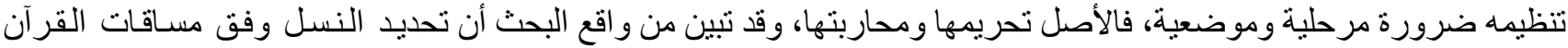

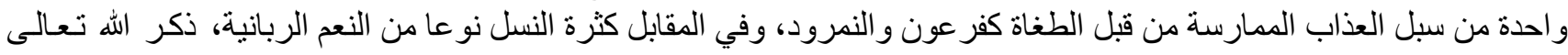

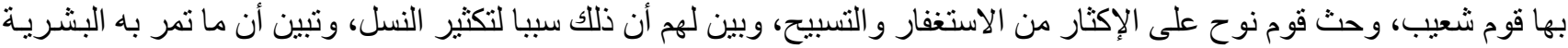

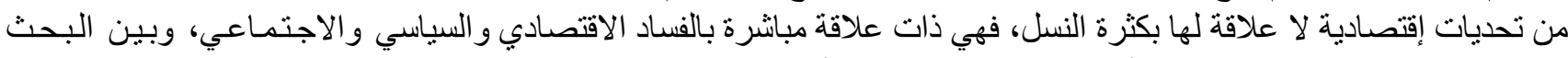

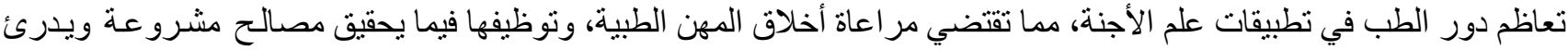

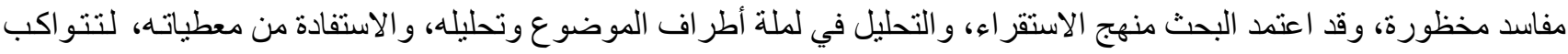
مع ما يرمي إليه الإسلام في قضايا النسل و التناسل.

الكلمات الافتتاحية: تنظيم النسل مفاهيم تطبيقيـة مقاصدية

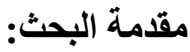

للإنجاب، ونشرًا للأمر اض التي أودت بحياة الكثير من البنات

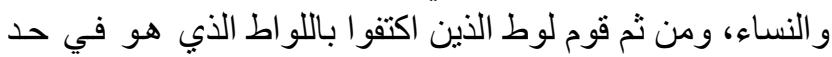

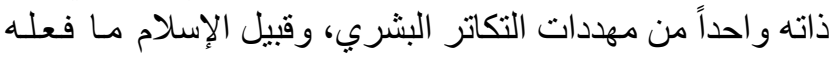

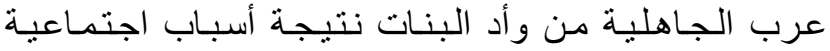

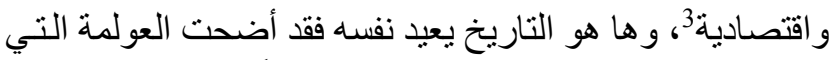

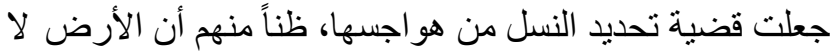

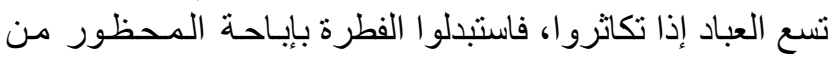

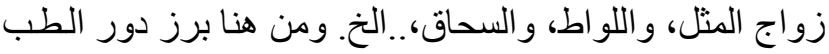

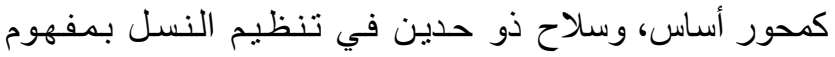

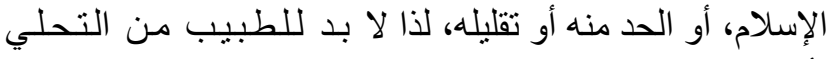

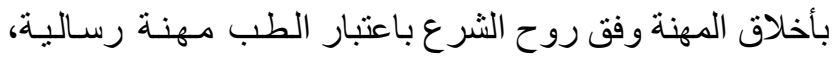

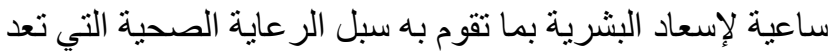

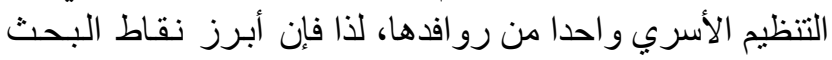

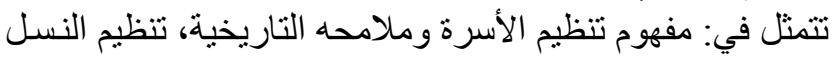

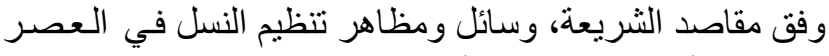

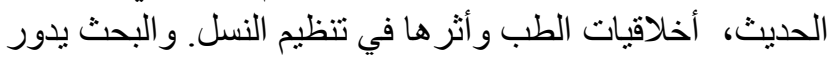

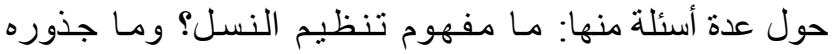

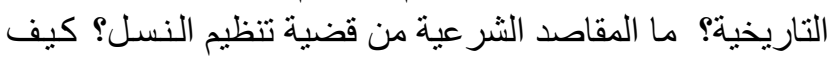

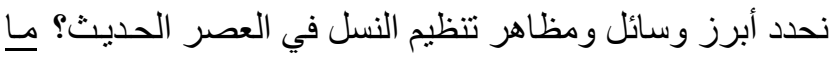

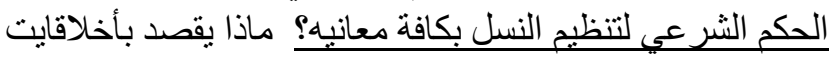

Corresponding author :

Ahmed El-Mogtaba Bannga Ahmed Ali

Kulliyyah of Islamic Revealed Knowledge and Human Sciences ,

International Islamic University Malaysia,

PO Box 10, 50728, Kuala Lumpur.

Email : mogtaba@iium.edu.my
يعد النسل قضية البشرية الأولى، لتعلقه بالإنسان وجوداً و عدمـاً،

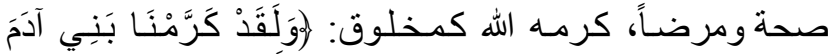

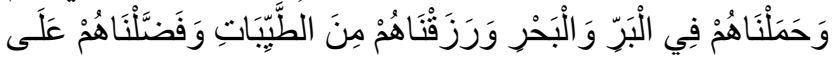

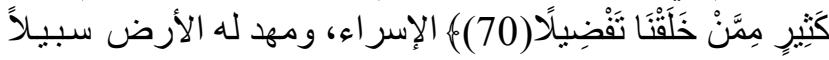

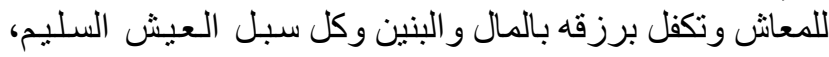

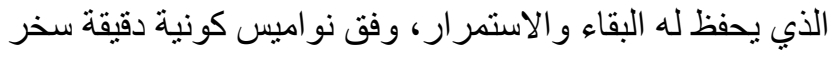

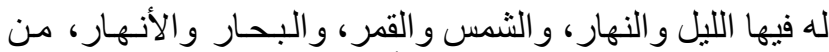

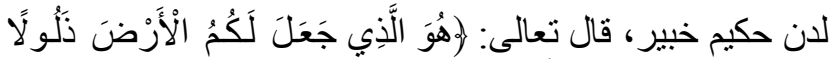

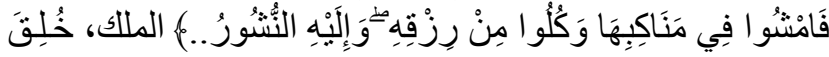

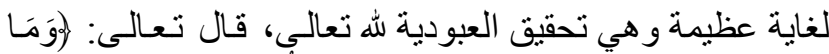

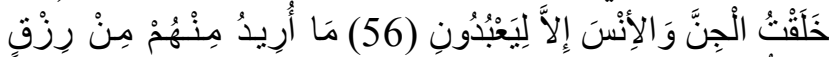

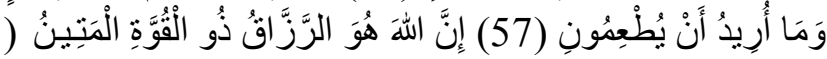

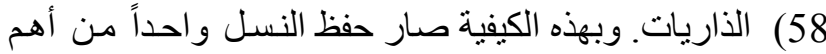

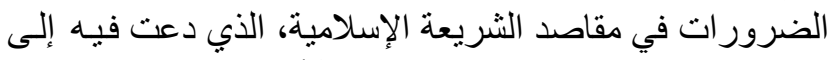

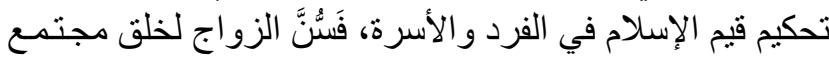

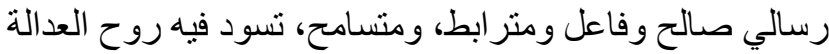

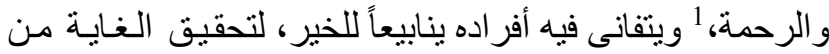

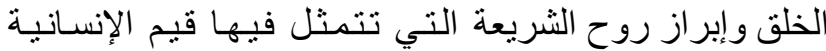

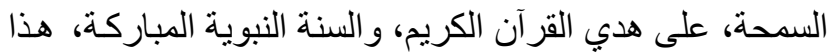

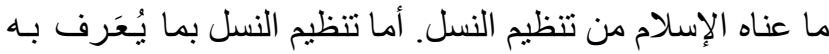

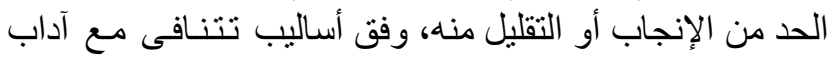

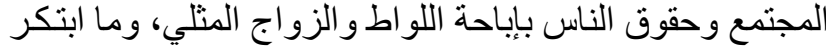

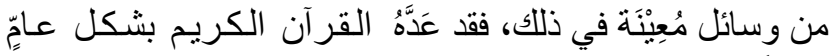

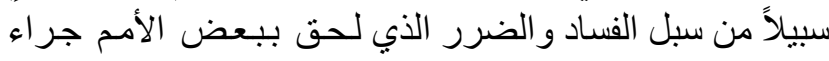

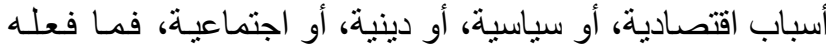

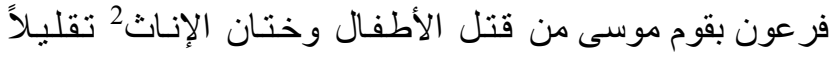


عليه فترة من الزمان تجاوزت ثمـان وثناثين سنـة، ومـع أنها

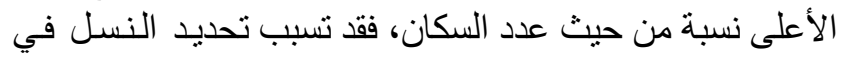

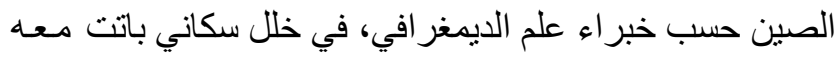

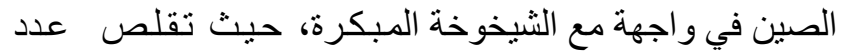

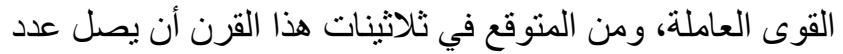

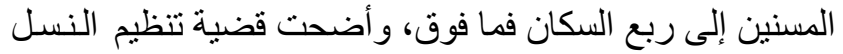

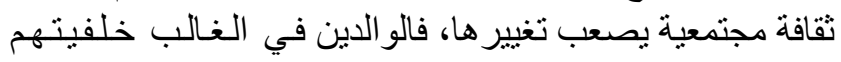
الأسرية ذات طفل واحد، مما يمثل هاوية ديمغر افية تولية اجهرها الصنين في مستقبل السنين. 10

الجذور التاريخية لتنظيم النسل ونتائجه:

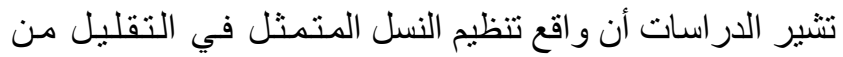
الإنجاب أو قطعه، ارتبط منذ القدم بـالمجتمعات البـات البشريـة،

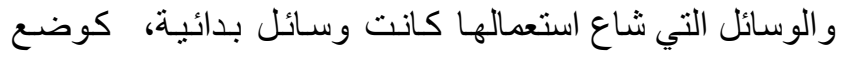
العسل، وأوراق السنط، ونبتة السيلفيوم التي تسبب الإجهاض التهاض

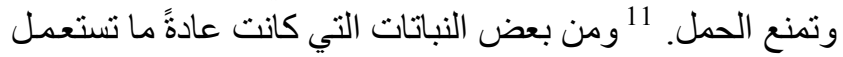

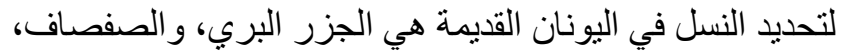

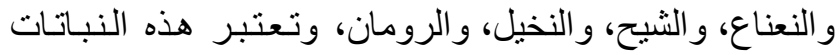

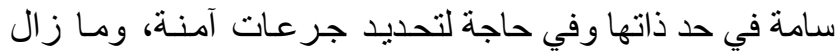

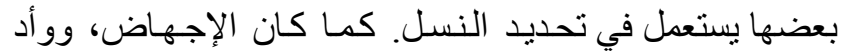
الأطفال، يمـارس نوع من أنواع تحديد النسل في القرل القرون

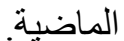

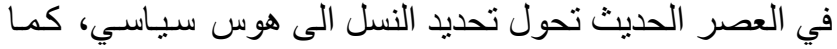

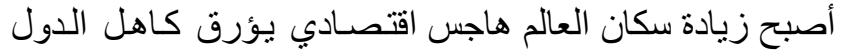

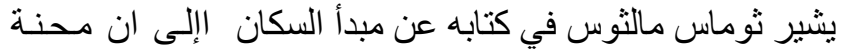

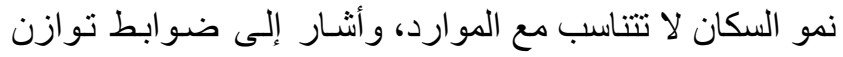

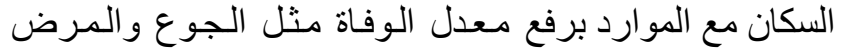

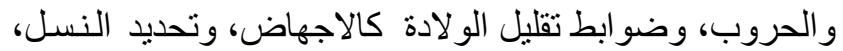

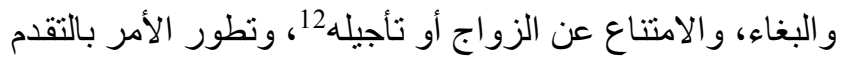
العلمي الذي أظهر الوسائل الحديثة في منع الحمل وتحديد النسل، التهاه

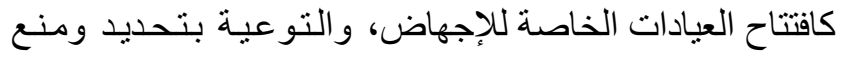

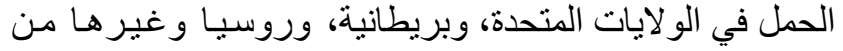

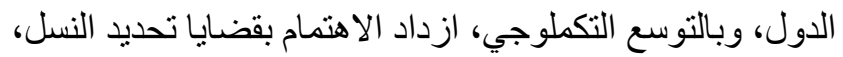

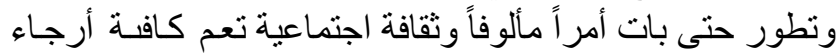

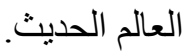

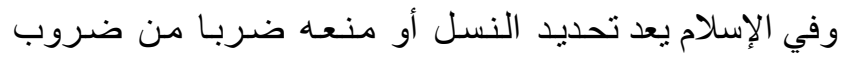

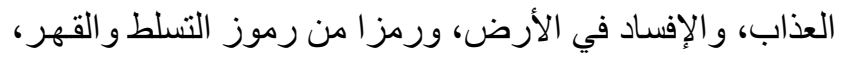

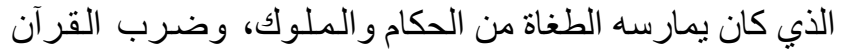

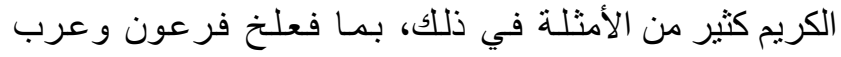

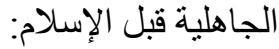

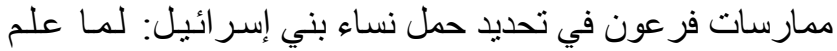

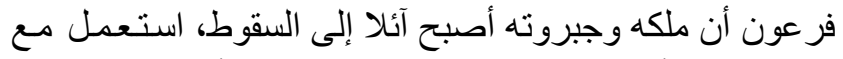

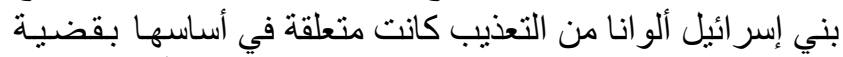

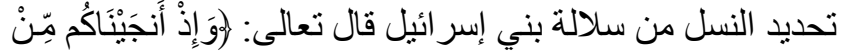

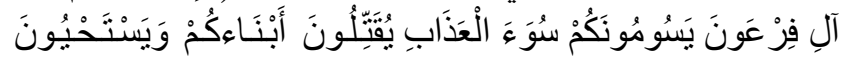

الطب وكيفية أثرها في تنظيم النسل؟ كما يهدف البحث إلى:

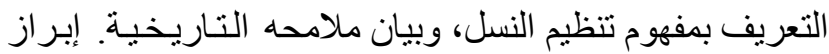

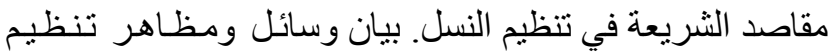
النسل في العصر الحديث. تحديد أبرز النقاط المعنية بـأخلاقيـات

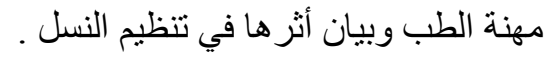

إثكالية البحث: يدور البحث حول تحديد المفارقة في مفهوم تتظيم النسل بين مقاصد الثريعة، وو اقعه عبر ملامحه التاريخية

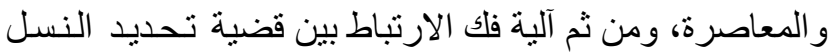

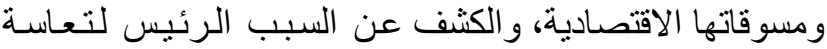

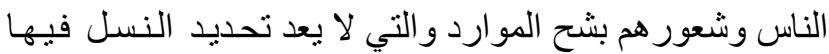

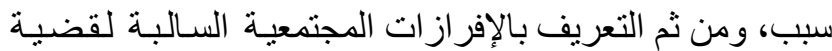

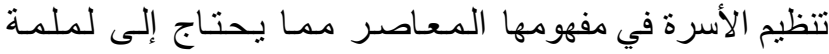

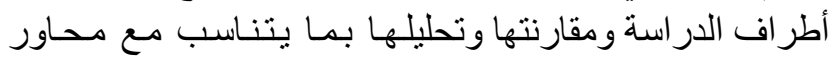

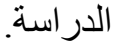

\section{مفهوم تنظيم النسل وجذوره التاريخية :}

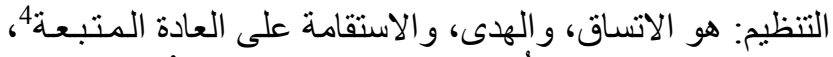

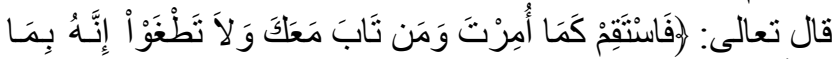

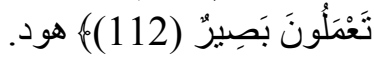

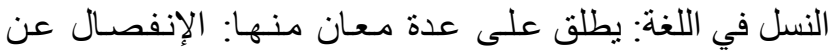

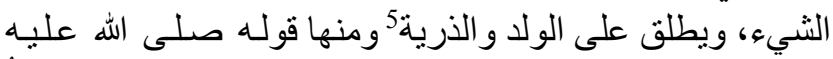

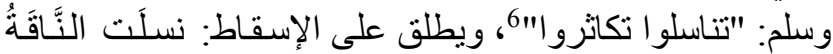

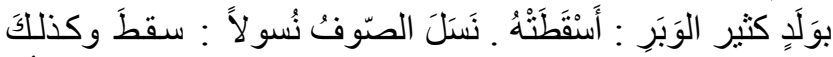

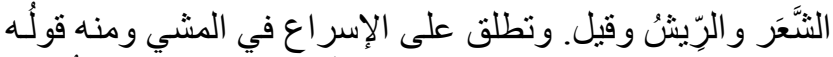

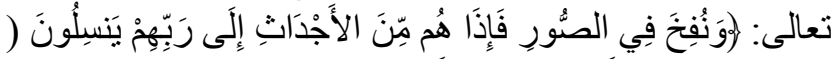

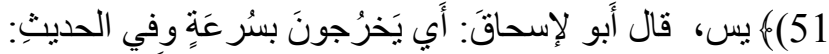

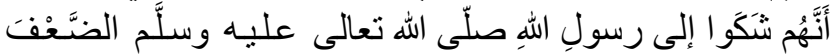

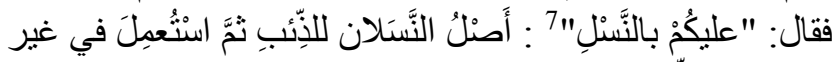
ذللكَ وفي الأسّساسِ.

تنطيم النسل اصطلاحاً: تقليل فرص الانجـاب أو تحديدهـا أو

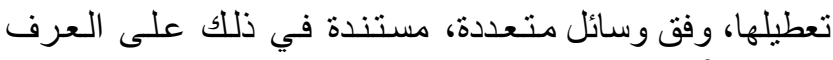
و القانون.

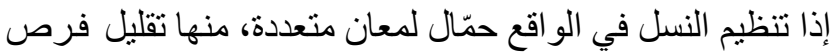

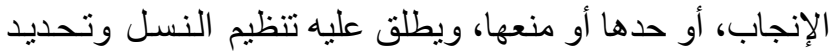

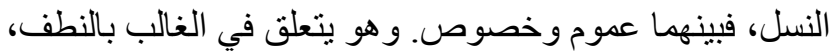

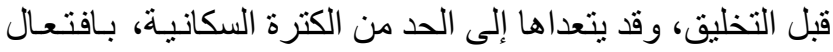

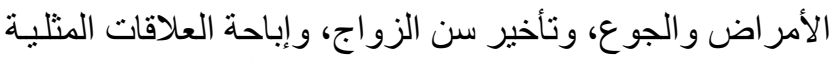

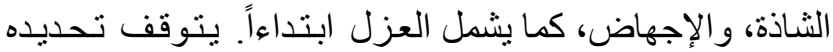

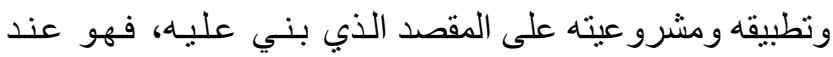
المسلمين في مفهومه وتطبيقاته مغاير لما هو عليه عليه في الفكر

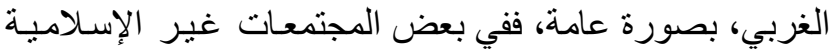
أخذ منحى تنظيم النسل مناحي تحديد النسل بالإكتفاء بالعدد القليل الإنيل

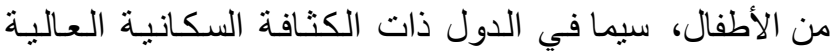

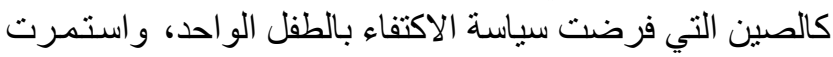




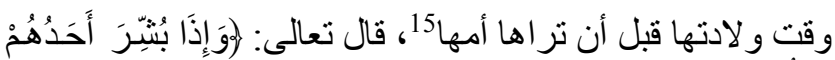

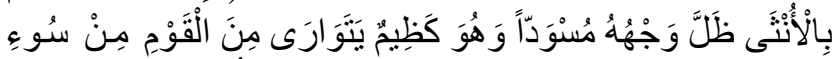

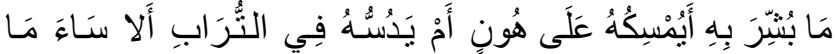

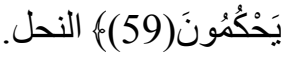

المقاصد الثرعية من تنظيم النسل: الناظر إلى مسـاقات الأدلة

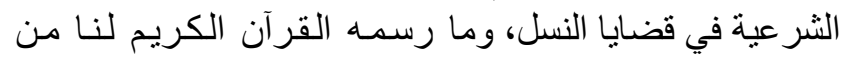

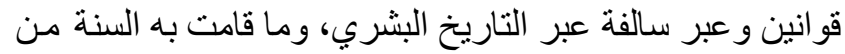

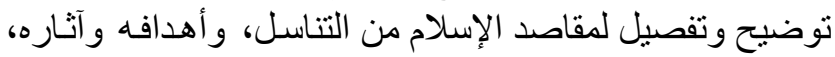
يمكن من خلاله استنباط بعض المقاصد المستقاة من تللك الأدلة التها

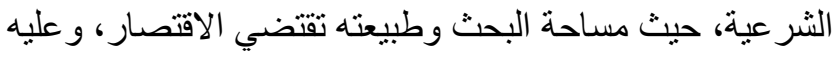
فإن أبرز النقاط المستوحاة من ذلك تتفصل في أن:

ـ الأصل في النسل التكثير : يصور القرآن أن التنـاسل وتكنثير

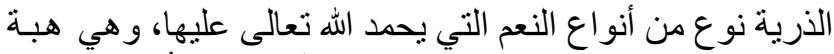

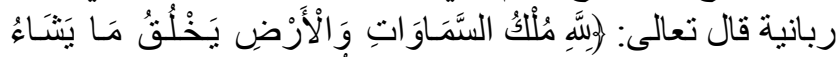

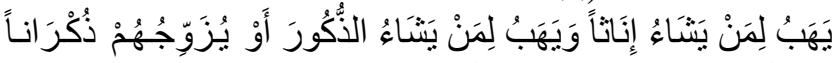

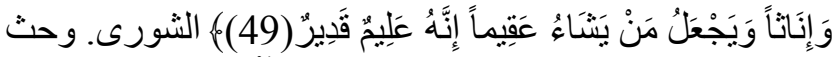

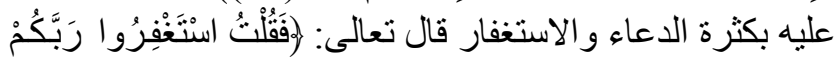

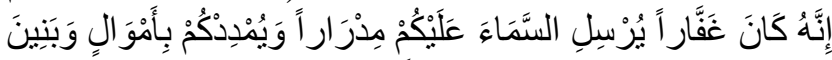

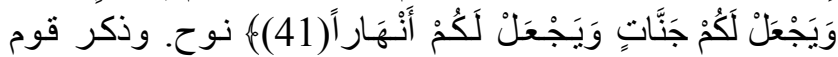

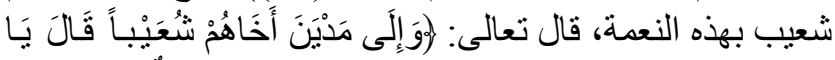

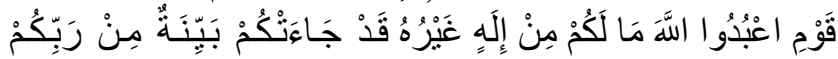

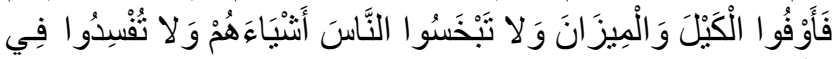

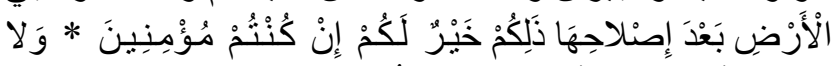

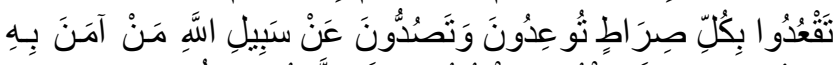

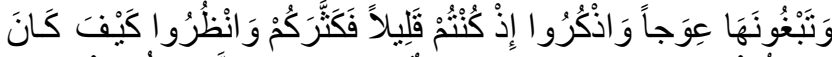

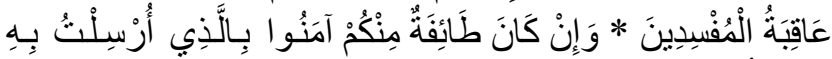

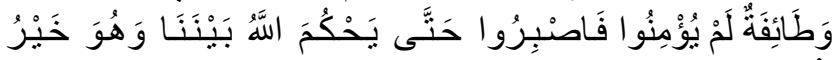

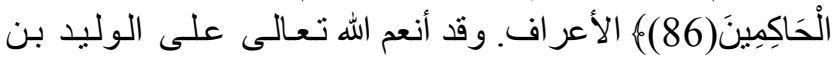

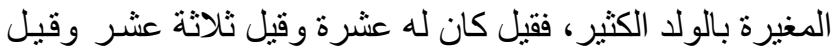

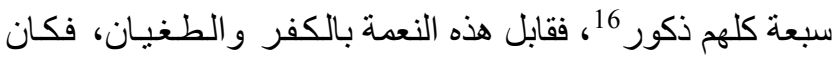

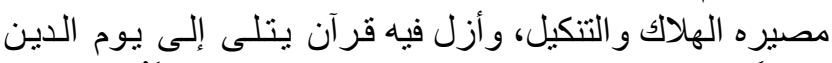

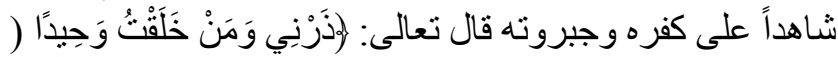

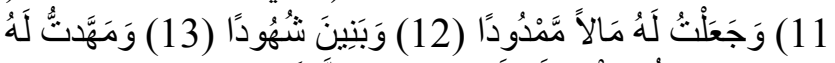

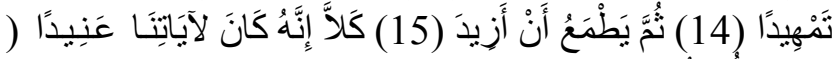

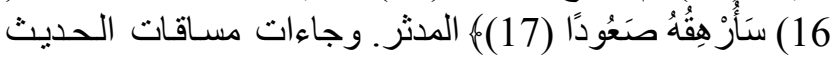

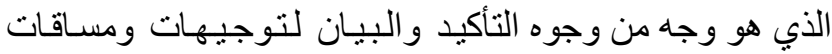

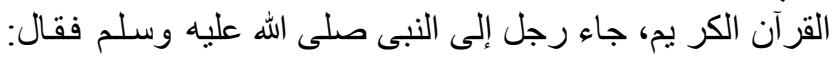

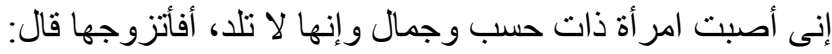

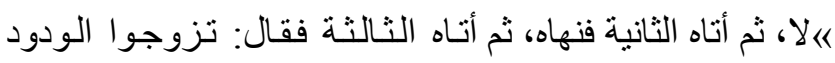

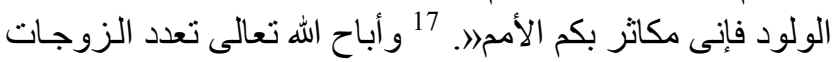

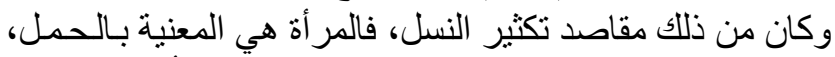

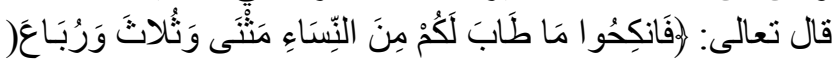

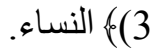

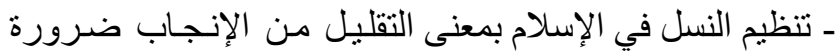

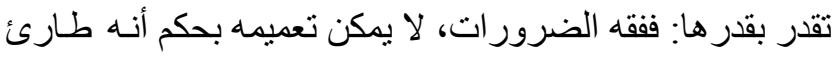

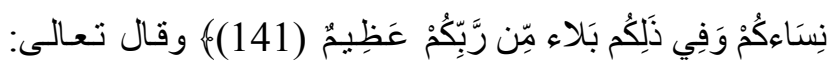

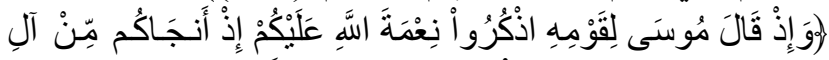

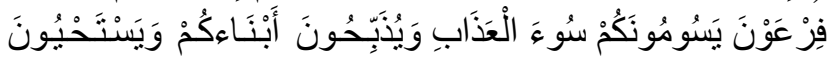

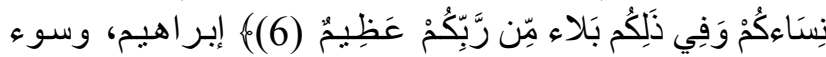

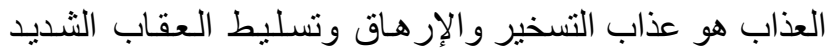

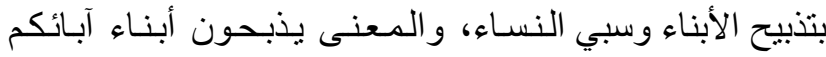

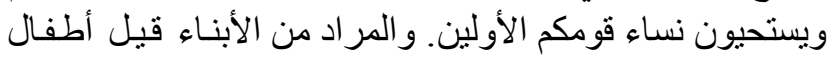

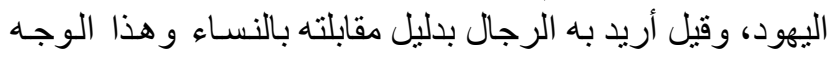

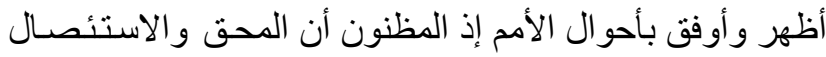

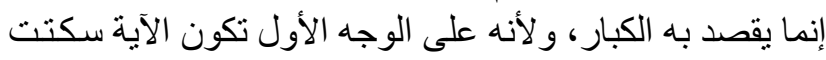

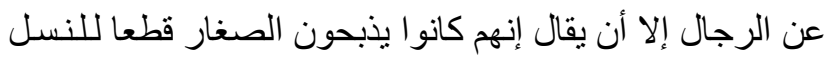

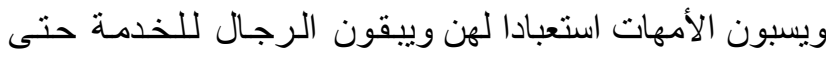

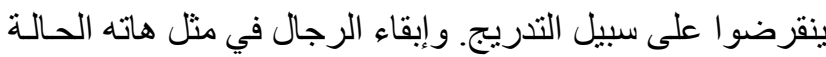

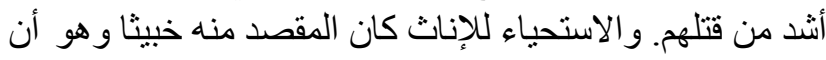

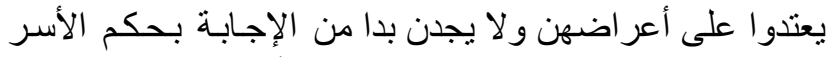

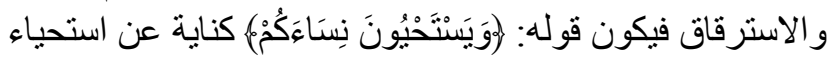

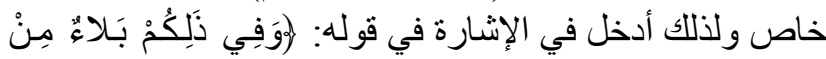

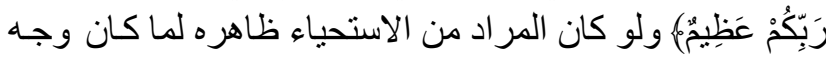

لعطفه على تلاك المصيبة. 13

ممارسات أهل الجاهلية بقتل الأو لاد ( الموؤدة): و المعني بقتل

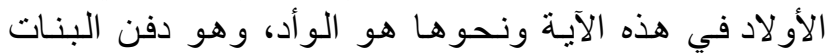

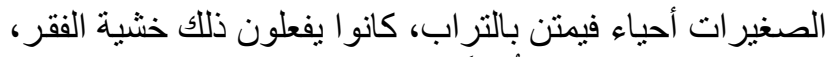

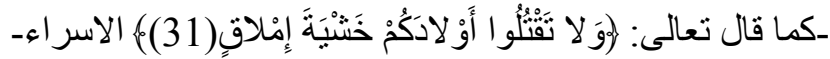

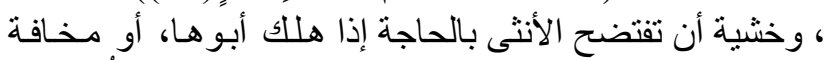

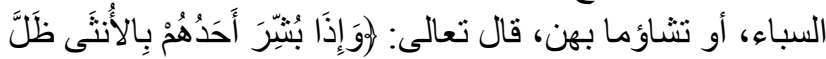

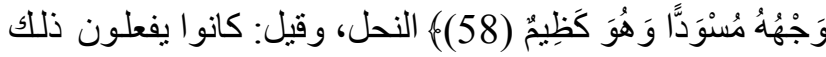

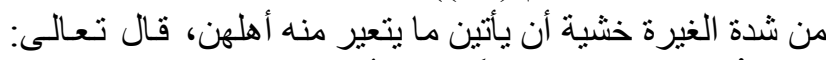

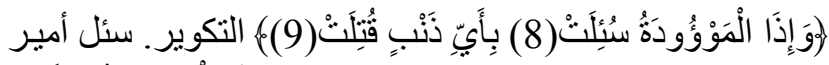

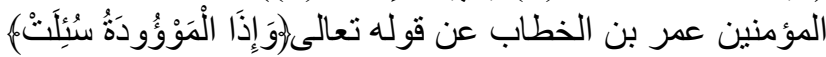

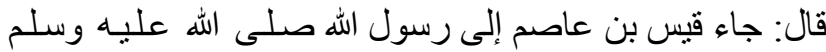

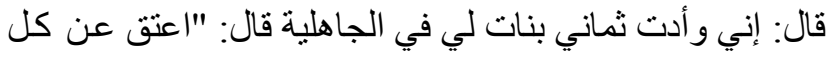

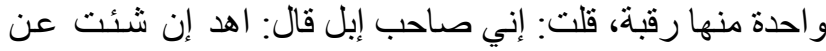

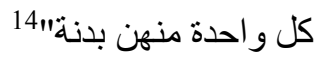

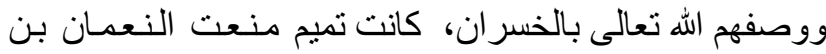

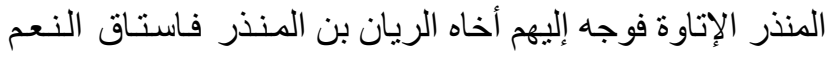

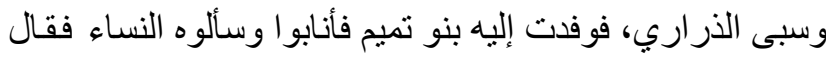

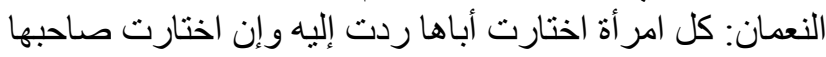

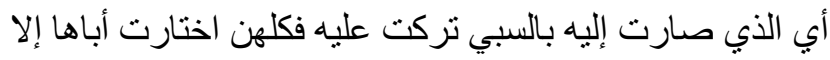

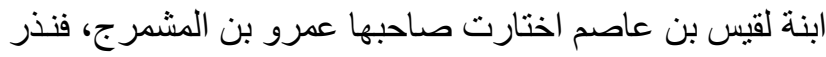

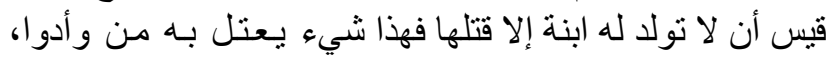

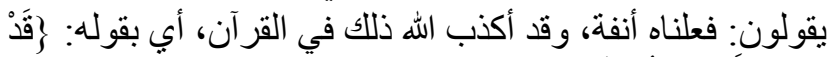

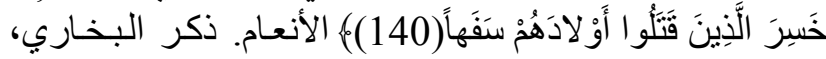

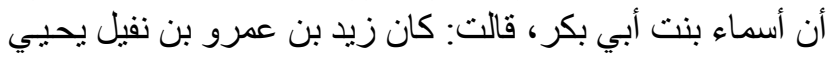

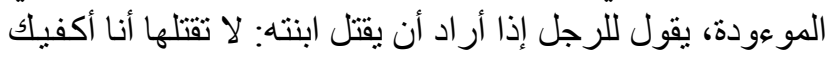

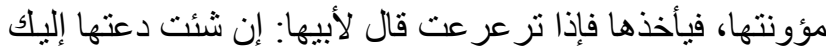

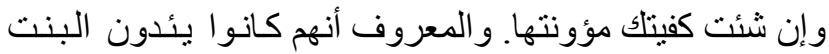


آخره"، 20 فالقوة البشرية أضحت في الو اقع المعاصر ، هي مفتاح

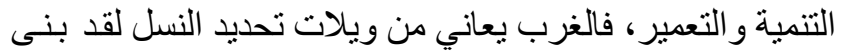

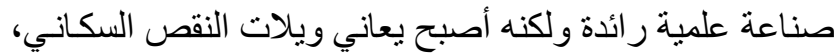
وصـار يبحث عمن يقوم بتشغيل العجلة الصناعية، كأمثنال أوربـا

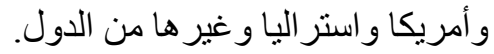

وسائل ومظاهر تحديد النسل في الواقع المـعاصـر و آثار هـا:

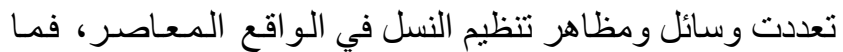

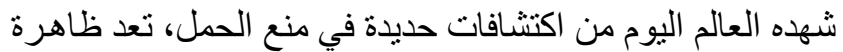

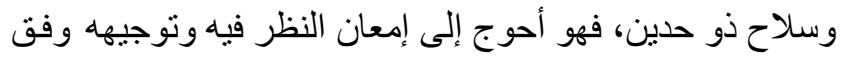

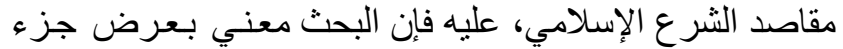

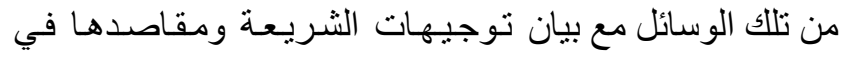
التعامل مع هذه الظاهرة. باعتبار ها وسائل مانعة لتحقيق انسيابية التناسل و التكاثر ، التي ارتضـاها الله تعالى لعباده سيما المؤمنين النين

منهم: - n

ـالعزل: قضية العزل قضية تاريخية، ويقصد بهـا أن يقذف وكان

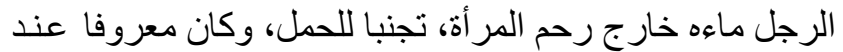

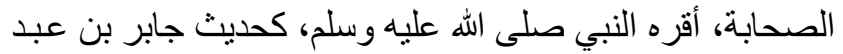

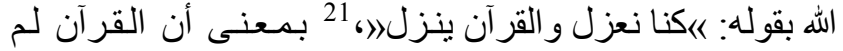

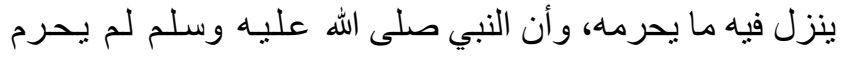

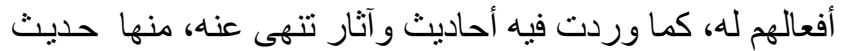

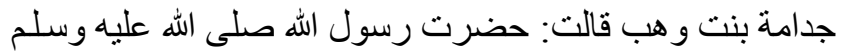
في أناس و هو يقول: هالقد همدت أن أنهي عن الغيلة....ثم سـألوه

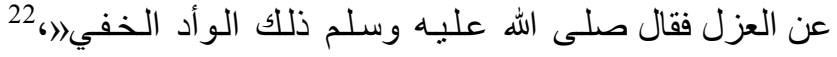
وسيأتي التفصيل فيه في باب الحكم الثر عي في تنظيم النسل

ـالوسائل المصنعة: شهد العصر الحديث ثورة صناعية في مجال تحديد النسل، ساهدت بشكل كبير في الحد من النسل وتقلقيله،

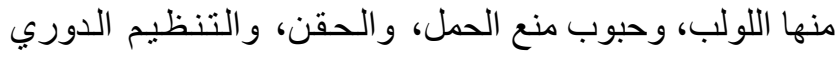

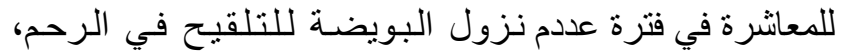

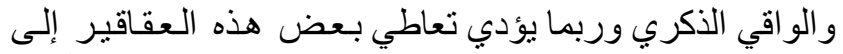

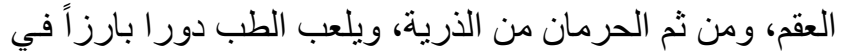

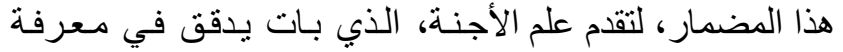

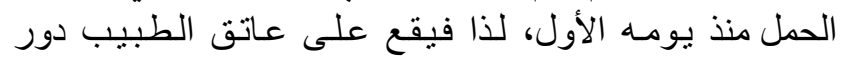

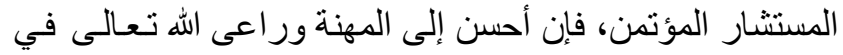

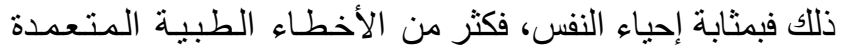
و غير المتعددة تؤدي إلى حالات العقم، لدى كثير من النساء.

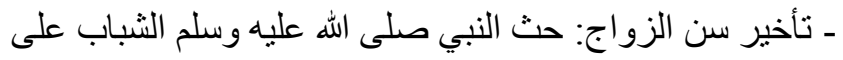

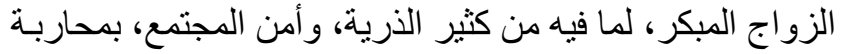

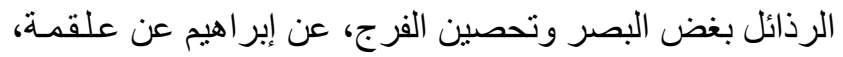

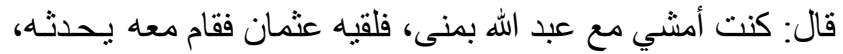

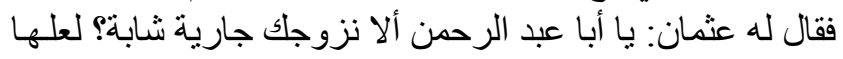

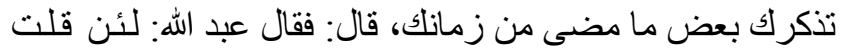

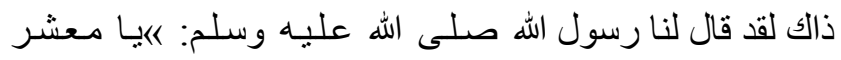

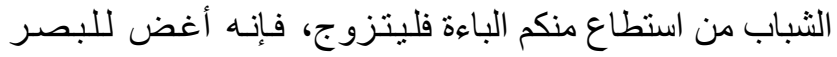

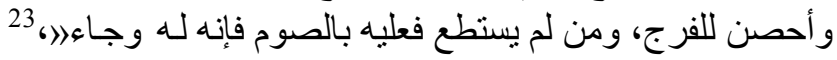

يزول بزوال الضرورة، وقد أشار العلماء لذلك بعدد من الأمثلة، إنها،

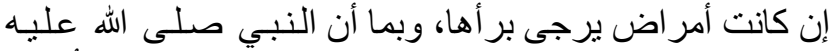

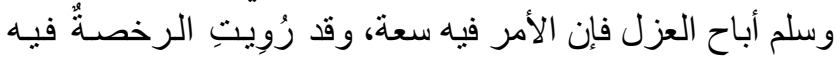

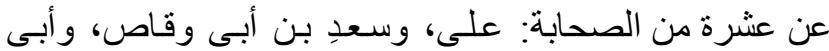

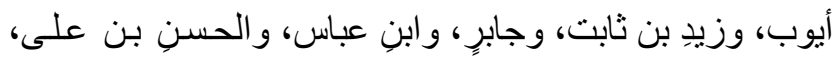

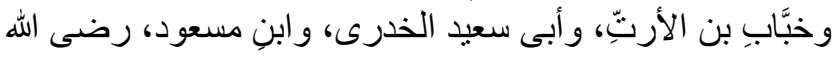
عنهم. 18

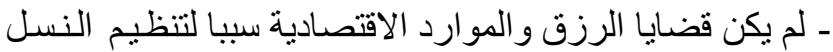

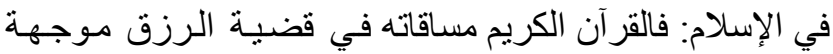

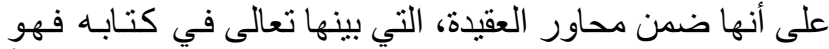

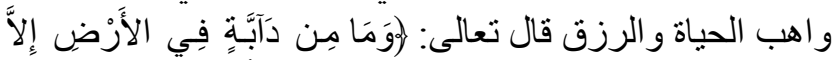

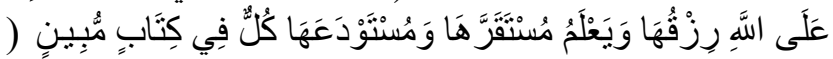

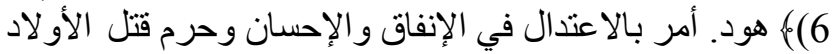

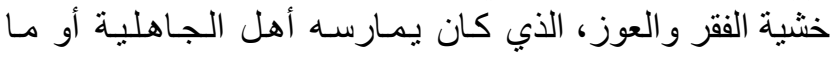

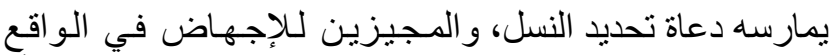

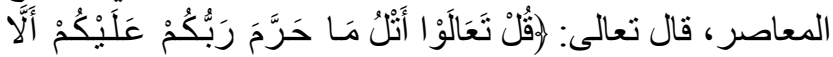

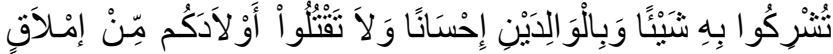

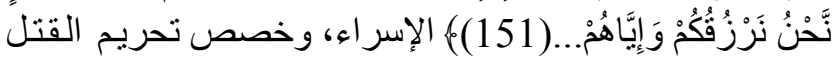
بخشية الإملاق لأنه هو الدافع لهم لقتل الأولاد، والنبي صلـى الأله

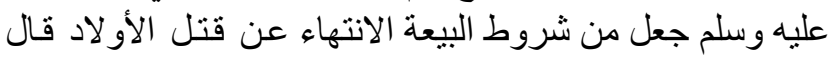

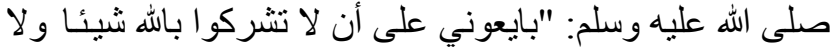

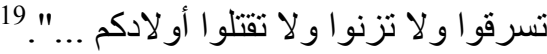

ـ تحديد النسل نوع من التعذيب وطريقة جالبة لسخط الله تعـالى:

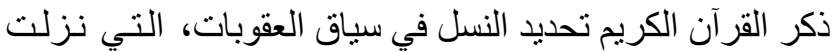

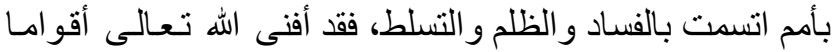
بسبب جبروتهم وتسلطهم، فقد أهلك الله تعـالى ابن نو فوح أمسام

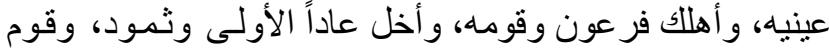

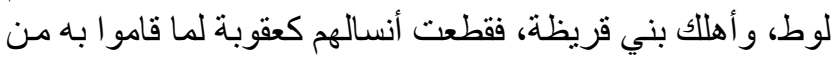

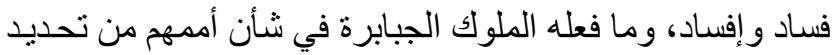

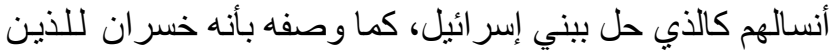

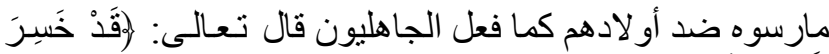

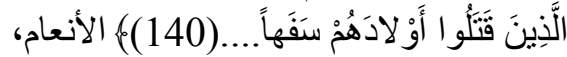

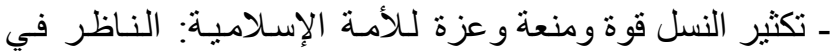

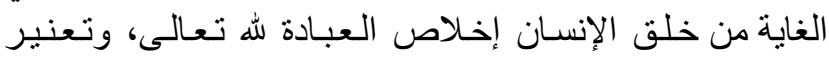

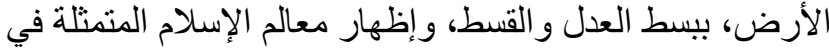

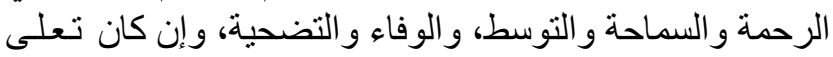

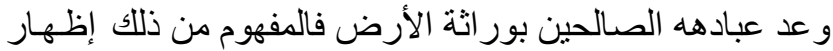

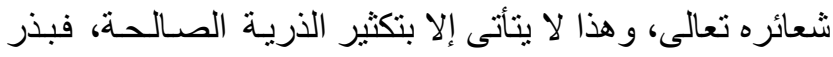

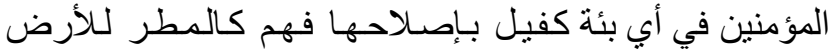

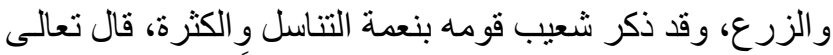

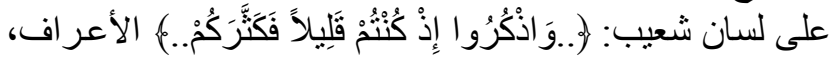

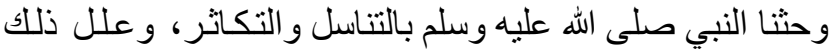

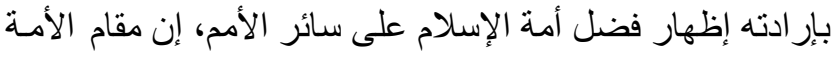

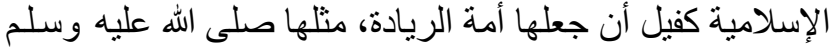

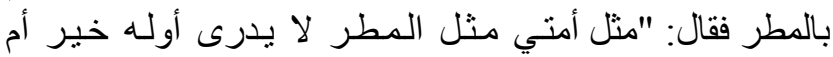


وفي بعض الأحاديث قلل النبي صلى الله عليه وسلـم من تأثنير

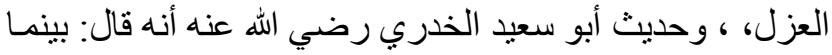

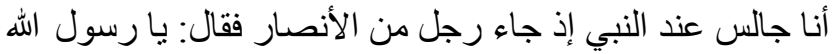

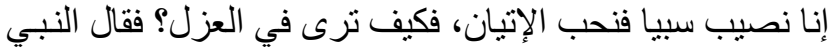

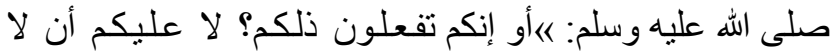

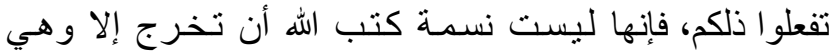

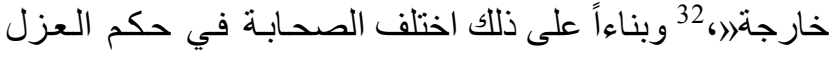

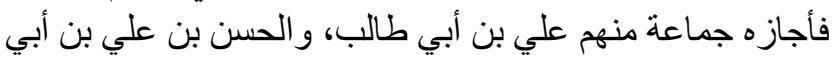

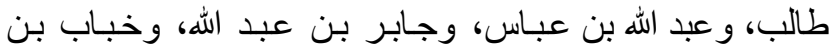
الأرت، وأبو أبوب الأنصاري، وسعد بن أبي وقاص، وجاب وأبو سعيد

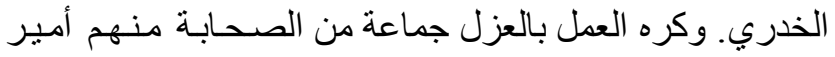
المؤمنين عمر بن الخطاب، وابن عمر ، وكان يضرب لئن بنيه عليه.

أما فقهاء المذاهب الأربعة، قالو ا بجواز تتظيم النسل المؤقت -

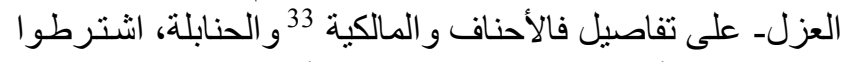

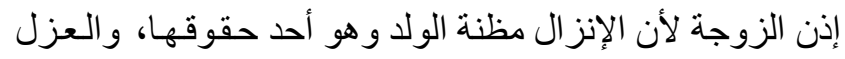

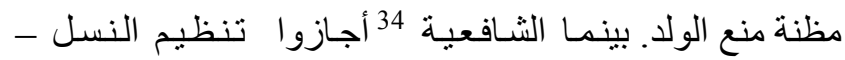

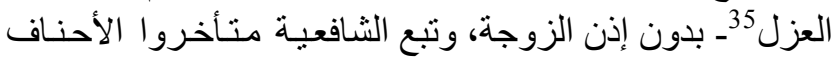

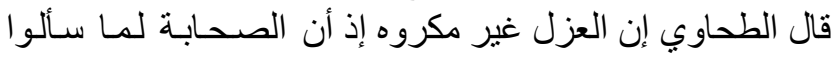

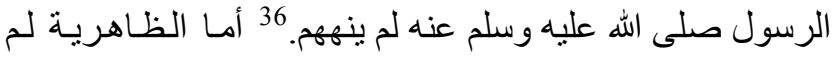

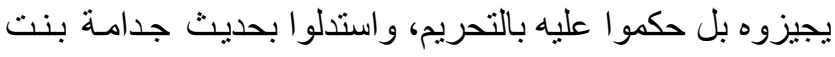

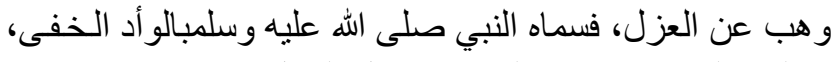

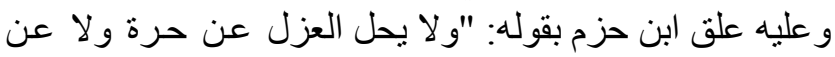

أمة ...

بناءاً على ما سبق من أقوال العلماء وموقفهم من قضيـة تنظيم

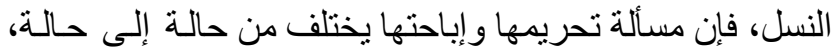

وفق الظروف المحيطة.

أخلاقيات الطب و أثرها في تنظيم النسل: أضحى الطب الحديث

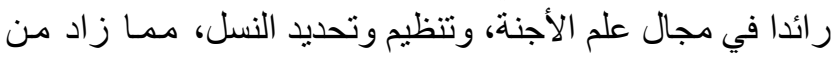

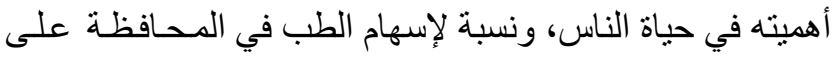

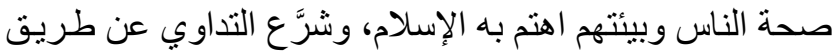

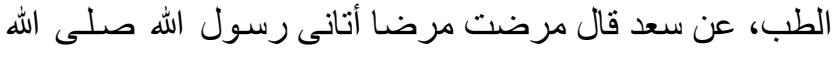

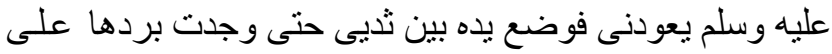

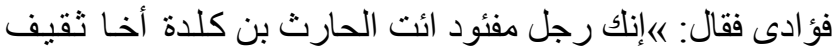

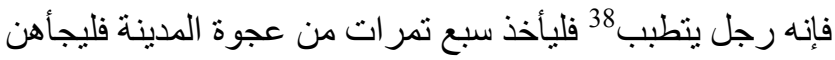

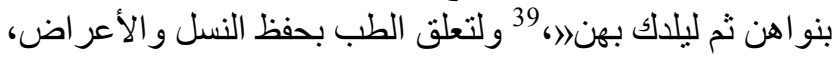

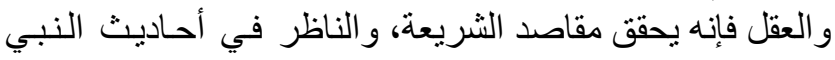

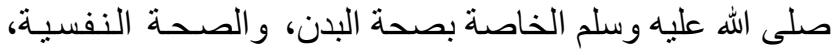

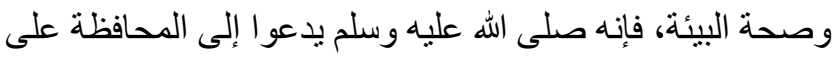

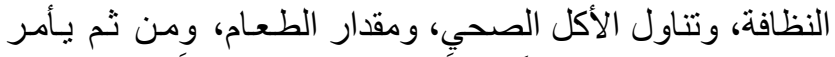

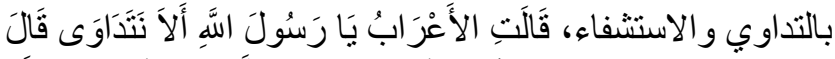

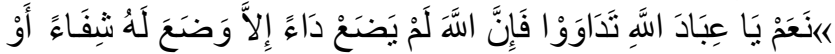

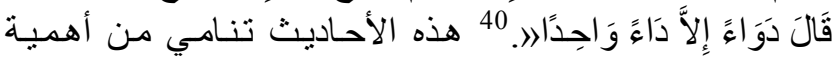

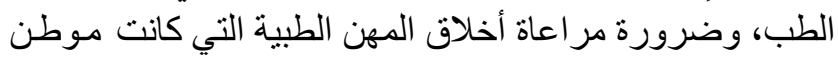

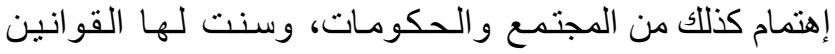
المنظمة للمهن الطبية، فأصبحت تللك القو انين تعتني بقياس كفاءة ولن لهاء

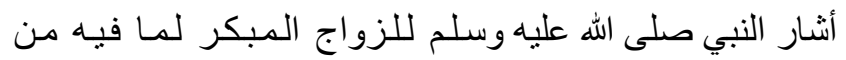

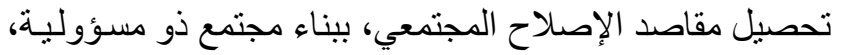

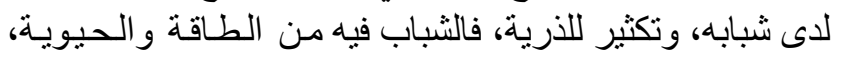

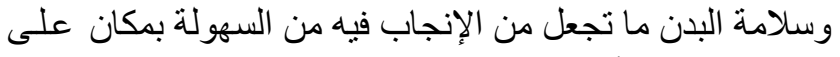

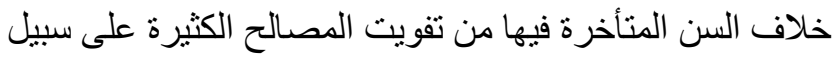

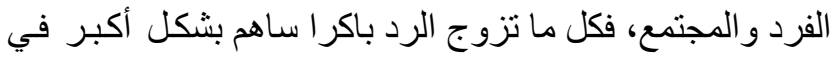

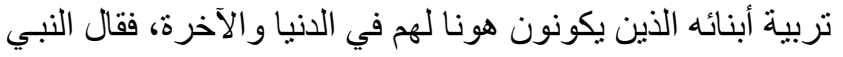

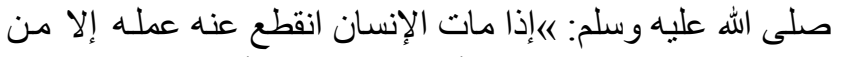

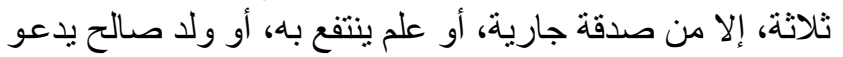

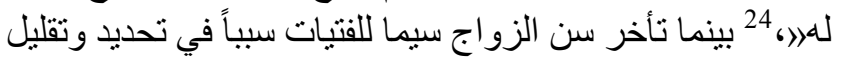

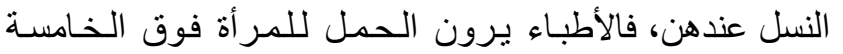

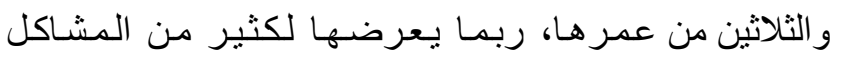
و المتاعب، وربما يولد الجبنين مع كثير من المشاكل الصحية. 25

الامتتاع عن المعاشرة الزوجية: من وسائل تحديد وتنظيم النسل

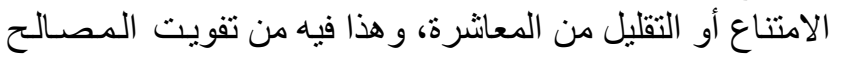

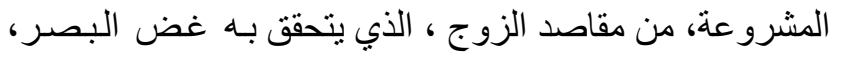

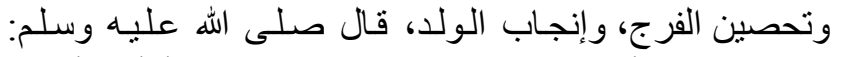
.....

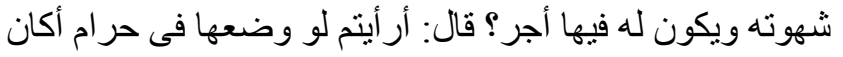

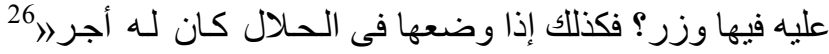

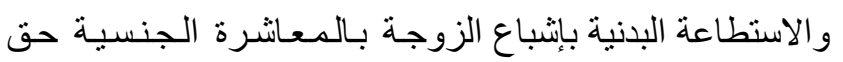

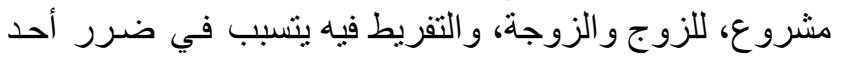

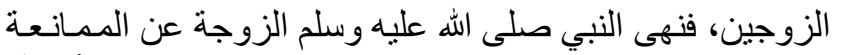

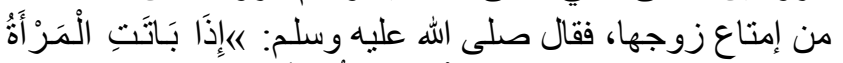

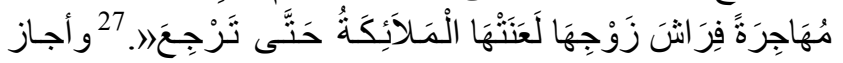

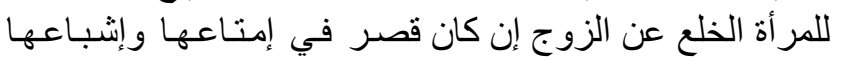

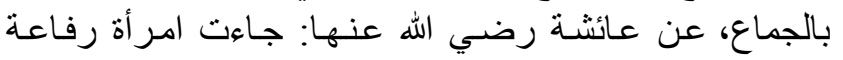

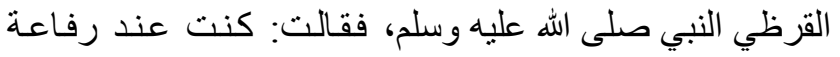

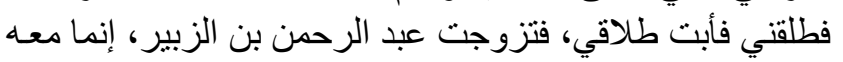

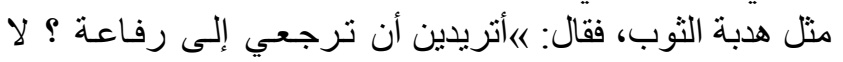

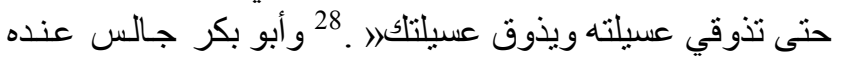

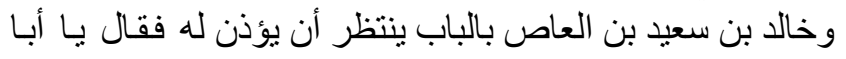

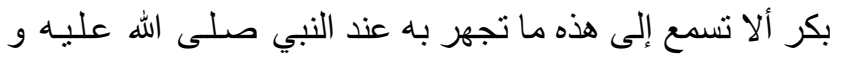

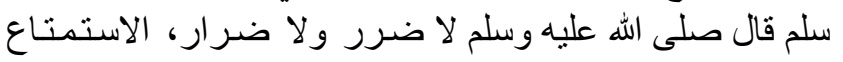
بالعلاقة الزو جية فالإمتناع من ممارسة.

\section{الحكم الشرعي لتنظيم النسل:}

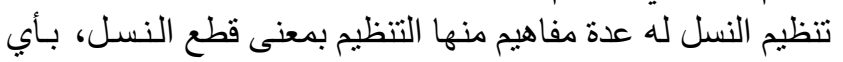

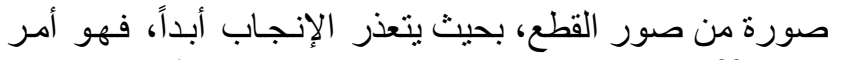

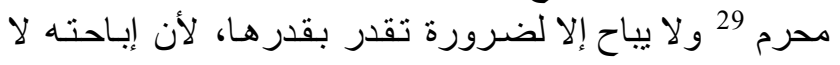

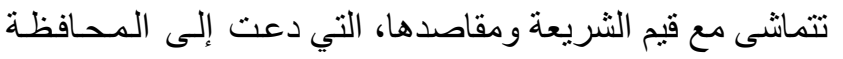

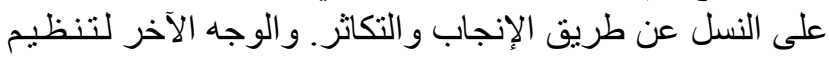

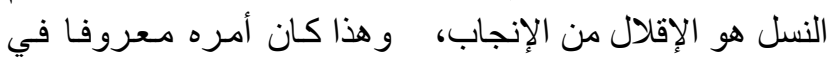

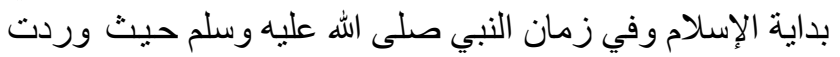

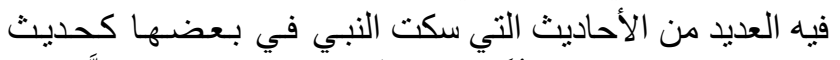

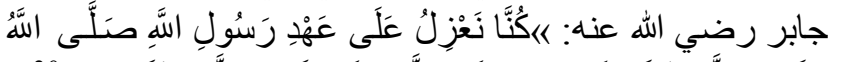

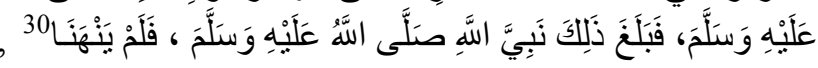


ذللك، وتقتضي الأمانة الطبية مصارحة المريض بعلته، وتقديم

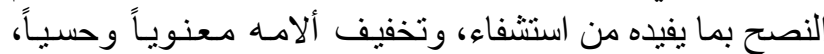

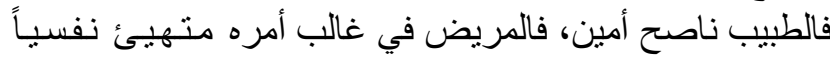

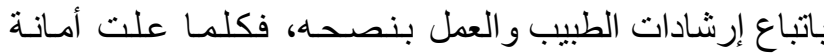
الطبيب كلما ز اد منفعته للناس وحقق سمعة طبية جيدة يكون بها إنا أسوة حسنة لغيره من الأطباء.

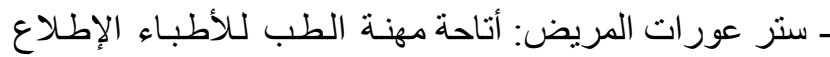

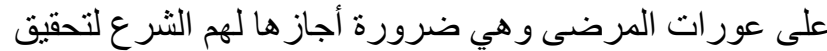

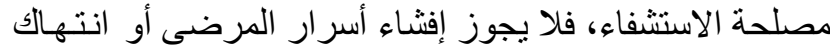

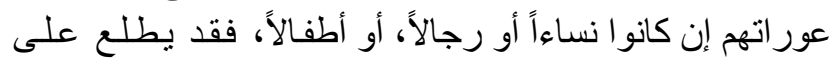

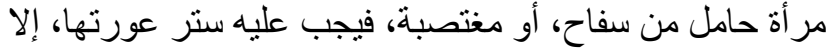
لاو اعي شرعية تقدر بقدر ها وقال صلى الله عليه وسلم: إالمسلم

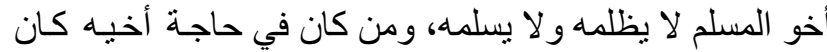

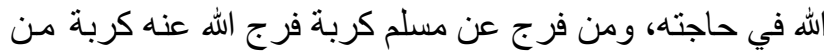

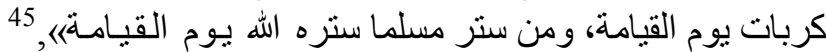

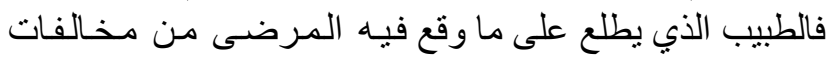

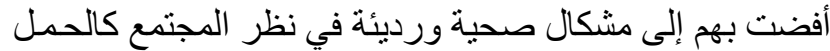

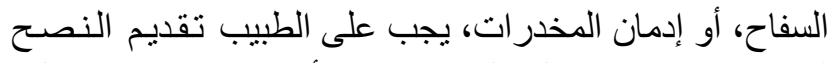

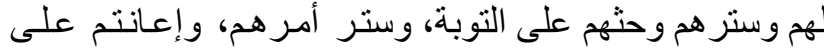

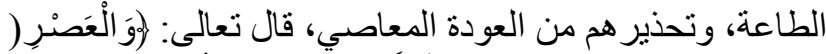

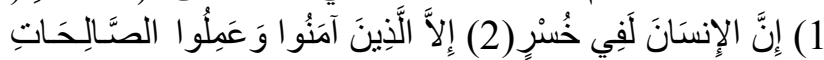

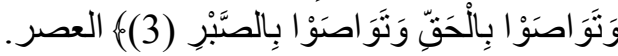

و الواقع يبرز دور المهن الطبية في مسائل تنظيم النسل، بشكل

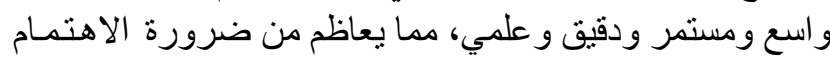

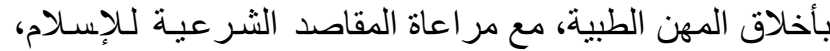
فالمقصد الإسلامي أولوياته تكثير النسل، و المحافظة على قضايا

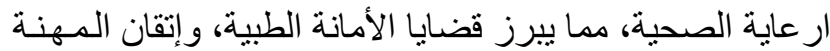

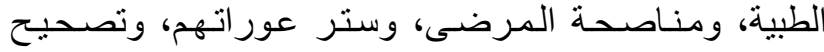

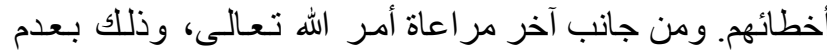

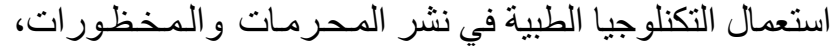

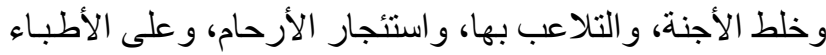

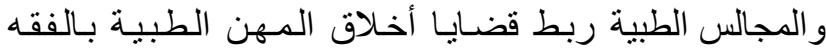

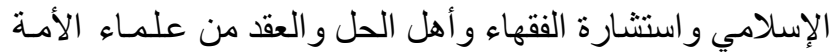
في إعمال الأدلة في فقه النوازل الطبية ـ و الله ولي التوفيق

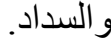

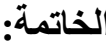

حفظ النسل واحداً من مقاصد الثرع، حيث حث على

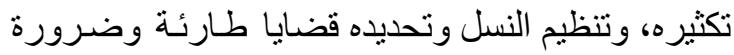
شر عية تقدر بقدر ها. تنظيم النسل بمفهومه الحديث كان عاملاً مساعداً لكثنير من المحظورات الإسلامية كاللو اط، و السحاق، وزواج المات

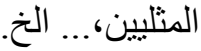
أثنار القرآن الكريم لتحديد النسل بمفهومـهـ المعـاصر

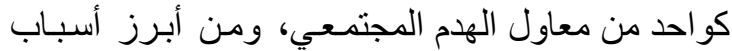

الطبيب، والتدريب المستمر، وكفالة حقوقهم المـاليـة، و الأهلية،

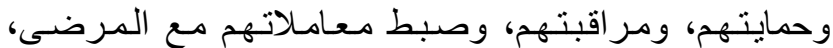

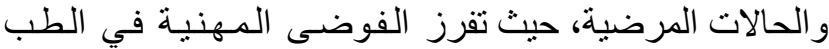

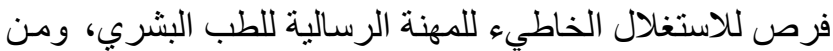

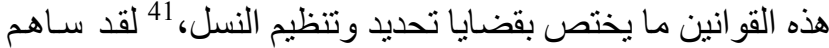

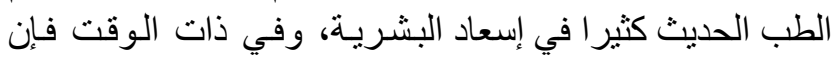
التدخلات الطبية في تنظيم النسل وتحديده زادت من تفنشي

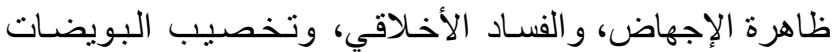

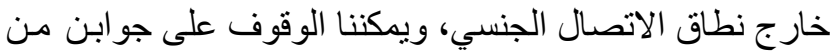

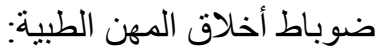

- إخلاص النية: النية مناط العمل، و الدافع الأسـاس في تطوير

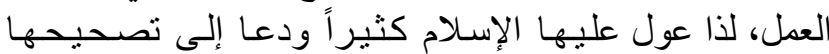

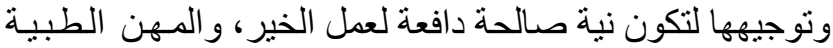

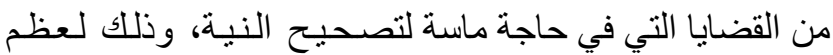

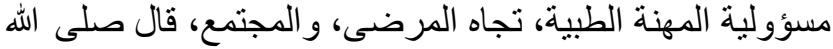

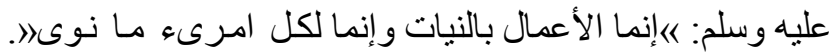

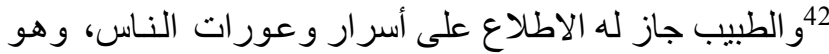

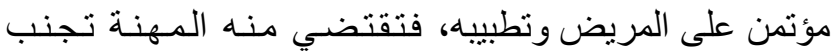
الأخطاء الطبية، وتجريد النية من الأطماع الثخصية، ولئهية والرذالة،

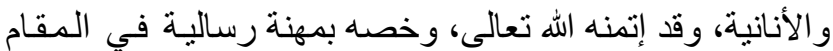

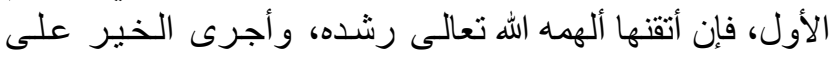
يدياه، وهي فرصة كبيرة للتقرب إلى الله تعالى.

ـ الكفاءة الطبية: تقتضي أن يكون الطبيب متقنا لعمله، منضبطاً

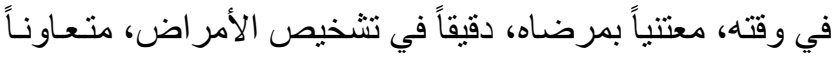

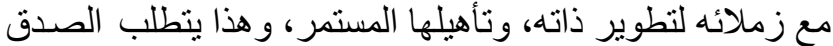

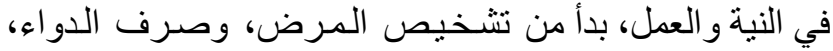

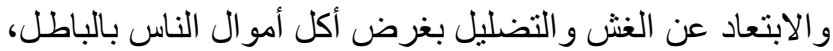

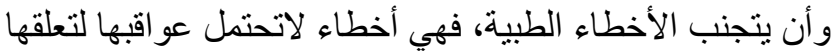

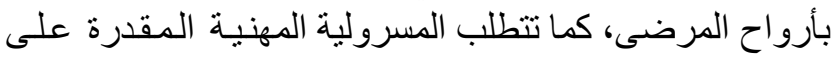
ممارسة الطب، قال صلى الله عليه وسلم: اهمن تطبب ولم الم يعلم

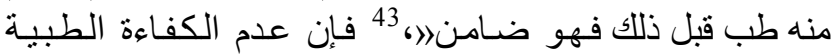

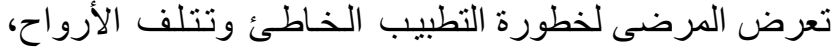

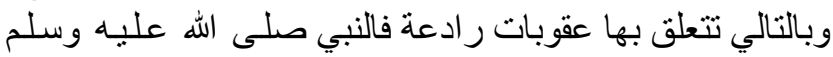

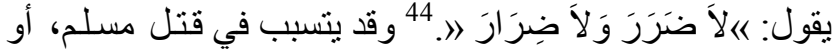

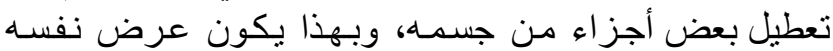

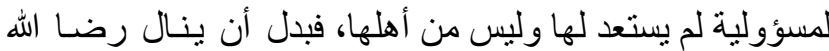

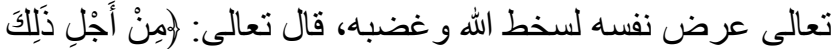

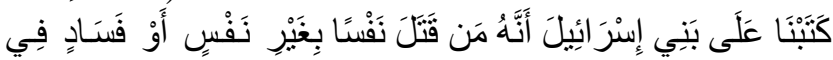

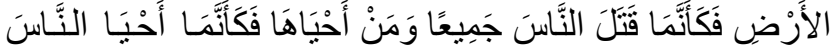

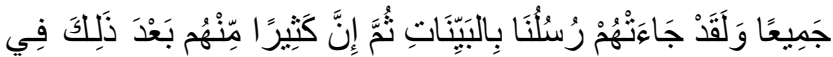

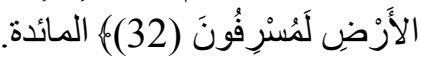

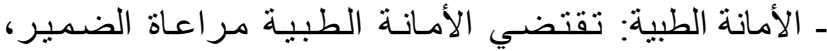

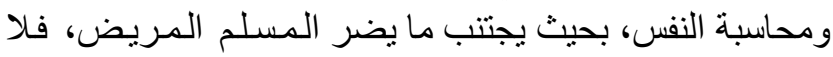

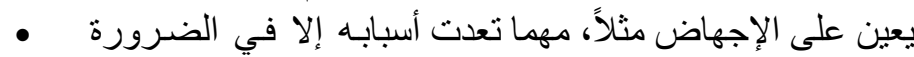
القصوى التي يحددها الطب، كمرض الأم وتشوه الجنين و غير الإنير 
الرسالة)

ابن العثيمين، فضيلة الثيخ محمد بن صالح العثيمين

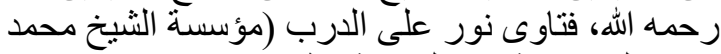

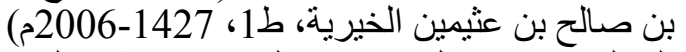

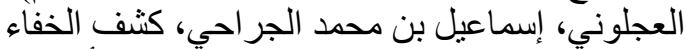
ومزيل الالباس عما اثتنهر من الاحاديث على الجئ ألسنة

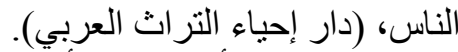

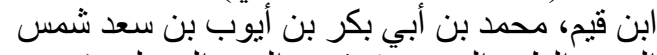

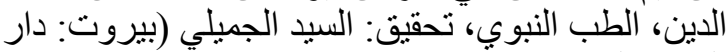

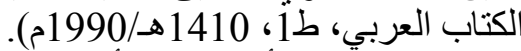

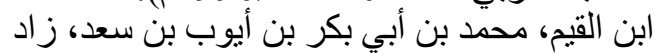

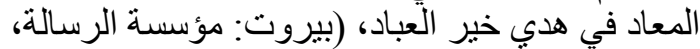

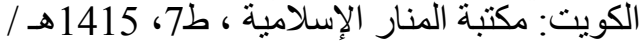

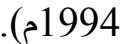

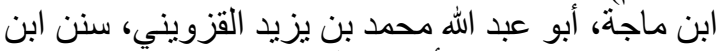
ماجه (موقع وزارة الأوقاف المصرية).

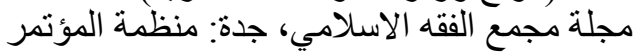
(الاسلامي).

محمد الطّاهر بن محمد بن محمد الطاهر بن عاشور التورير

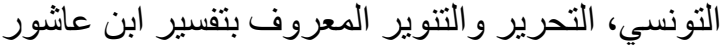

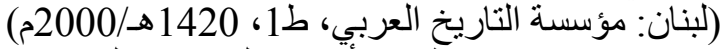

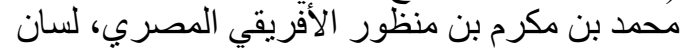

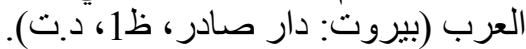
محمد عبد الرؤوف المناوي، التوقيف دادي على مهمات

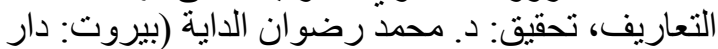

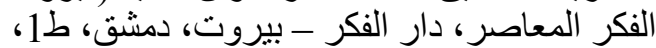

(01410

مسلم بن الحجاج، صحيح مسلم (بيروت: دار الجيل:

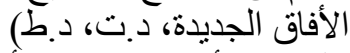

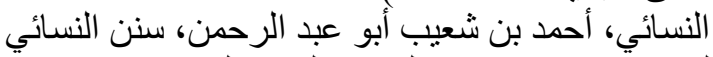

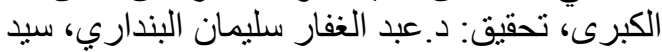
كسروي حسن (بيروت: دار الكتب العلمية، طُّان، 1411

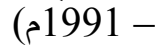
نظام الدين الحسن بن محمد بن حسين القمي النيسابوري، غر ائب القر آن ور غائب الفرقان، تحقيق: الثين زين زكريا عمير ان (لبنان: دار الكتب العلمية، ط1، 1416 هـ ـ ـ

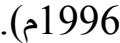

وهبة الزحيلي، الفقه الإسلامي و أدلته ( دمثنق، سورية:

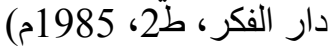
http://hayatouki.com/pregnancy/ -content/1861257

http://www.med-ethics.com (https://arabic.rt.com/news/798541 تاريخ: 20/10/2016

: http://alarb.co/new/detail397654.html

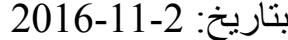

: http://alarb.co/new/detail397654.html

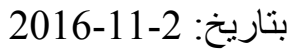

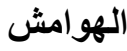

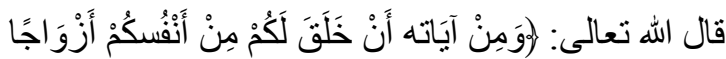

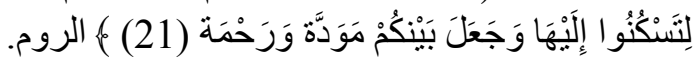

الاستبداد و الفساد الاقتصادي والديني و الاجتماعي عبر

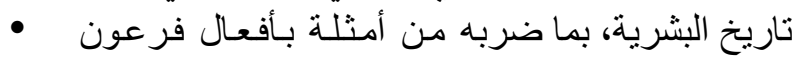

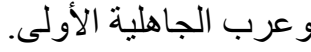

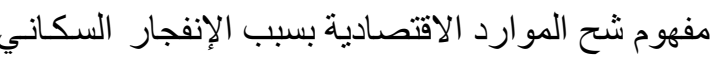

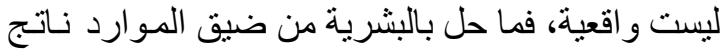

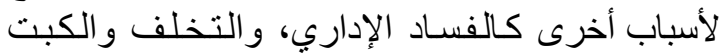

وضياع العدالة المجنمعية.

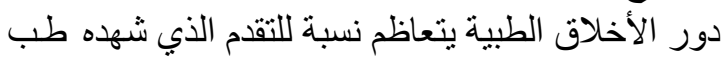

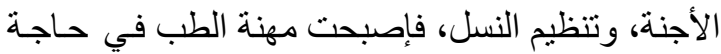
لضو ابط أخلاقية من الأمانة، والصدق، وحسن التهن التطبب،

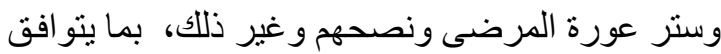
مع روح الثرع لما يسهم في التنمية البشرية.

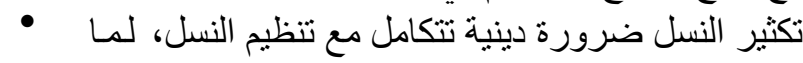

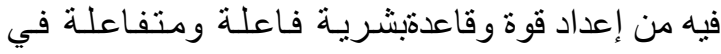

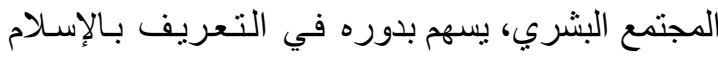

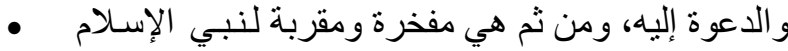

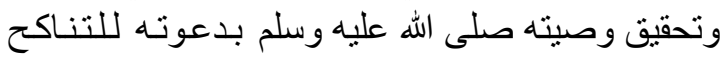

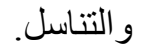

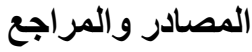

ابن الأثير، أبو السعادات المبارك بن محمد الجزري،

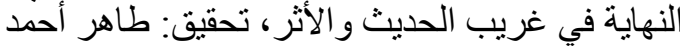

الز اوى ـ محمود محمد الطناحي (بيروت: المكتبة الطنة

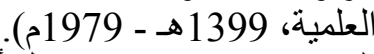

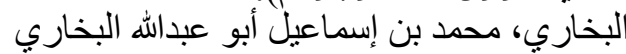

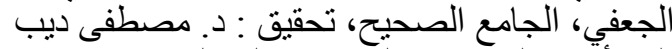

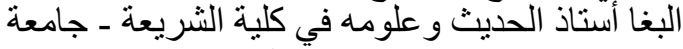

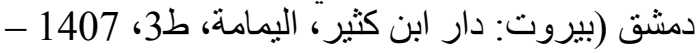

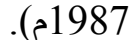

الترمذي، محمد بن عيسى أبو عيسى، سنن الترمذي، تحقيق: أحمد محمد شاكر و آخرون (بيروت: دارئ دار إحياء

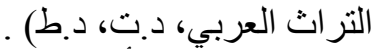

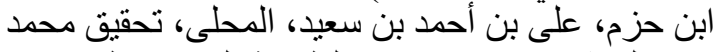

منير الدمثقي (مصر : إدارة الطباعة المنيرة، ط1، بله

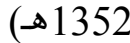

ابن عبد البر، يوسف بن عبد الله بن محمد، التمهيد لما

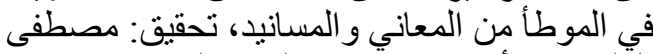
العلوي، الأستاذ محمد عبد الكبير البكري البكي

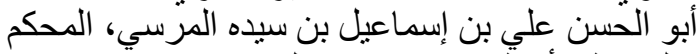

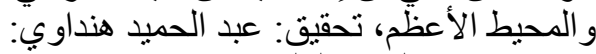

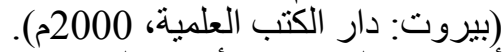

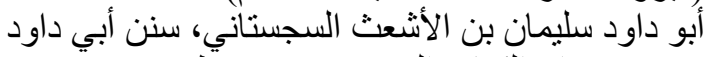

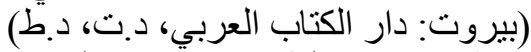

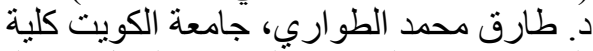

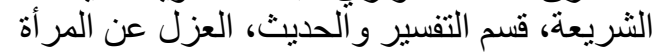
در اسة شرعية وطبية، راجع موقع: .Www.zawjan.com

الطبر اني، سليمان بن أحمد بن أيوب، المعجم الكبير ، تحقيق: حمدي بن عبد المجيد السلفي (الموصل: مكتبة المعبة المبن العلومو الحكم، ط2، 1404 - 1983).

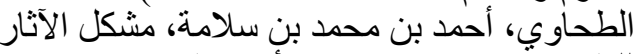
للطحاوي، تحقيق: شعيب الأرناؤط (بيروت: مؤسسة الأنارة 
نظام الدين الحسن بن محمد بن حسين القمي النيسابوري،

غر ائب القرآن ور غائب الفرقان، تحقيق: الثيخ زكريا عميران (لبنان: دار الكتب العلمية، ط1، 1416 هـ ــ ـ

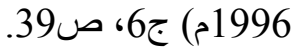

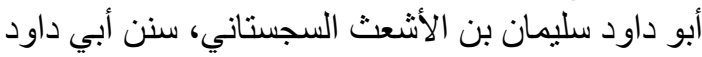

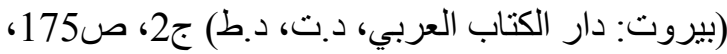
حديث رقم20. ابن القيم، محمد بن أبي بكر بن أيوب بن سعد، زاد المعاد

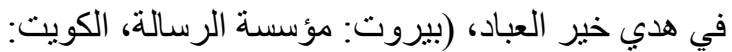

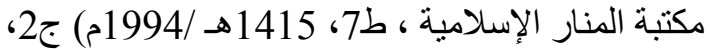
صاري البخاري، محمد بن إسماعيل أبو عبدالله البخاري الجعفي،

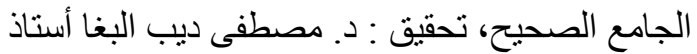
الحديث و علومه في كلية الثريعة - جامعة دمشق النق (بيروت: دار ابن كثير، اليمامة، ط3، 1407 - 1487مة 1987م)

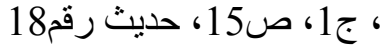

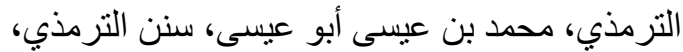

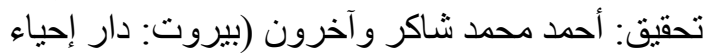

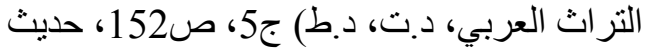
رقم2869. صحيح البخاري، ج5، صنوا21998م.

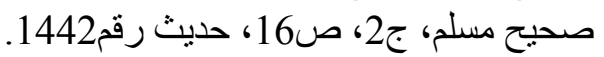
صحيح البخاري، ج7، ص273، صن، حديث رقم2435.

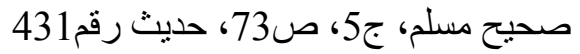
http://hayatouki.com/pregnancy/ -content/1861257

الإمام مسلم بن الحجاج، صحيح مسلم (بيروت: دار

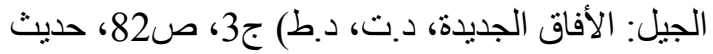

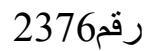

صحيح البخاري، ج17، ص13، صديث رقم5194.

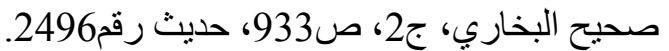
أ. د. و هبة الزحيلي، الفقه الإسلامي و أدلته ( دمثق،

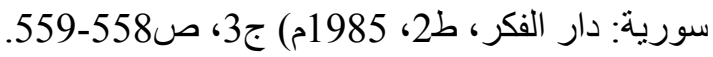

صحيح مسلم، كتاب النكاح باب حكم العزل، ج2، دأح،

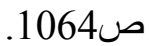
صحيح مسلم، كتاب النكاح باب حكم العزل، ج2،

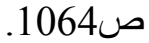

صحيح مسلم، كتاب النكاح، باب حكم العزل، ج2، صاصن

قال مالك رحمه الله تعالى: "لا يعزل الرجل عن المر أة إلا

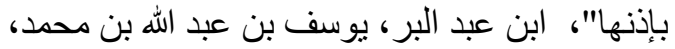

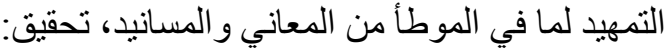
مصطفى العلوي، الأستاذ محمد عبد الكبير البكري، ج3، الكئن ص149. الفقه الإسلامي و أدلته، ج3، ص554 العزل هو نوع من أنو اع موانع الحمل، وكان شائعا في

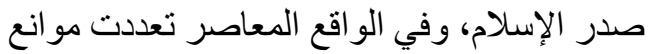
الحمل، من دواء و غير ها، قال الزركثي: وبناء: "يجوز

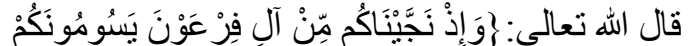
.2

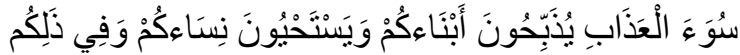

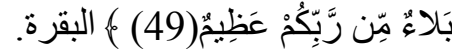

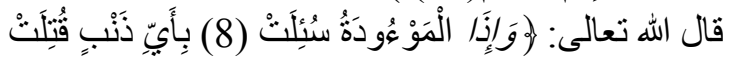
(9) - (9) م) التكوير.

محمد بن مكرم بن منظور الأفريقي المصري، لسبان

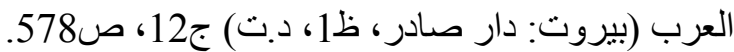
محمد عبد الرؤوف المناوي، التوقيف على مهمات

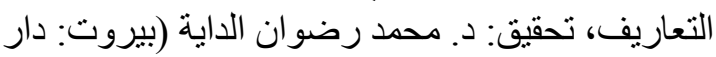
الفكر المعاصر، دار الفكر - بيروت، دمشق، ط1،

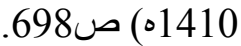

العجلوني، إسماعيل بن محمد الجر احي، كثنف الخفاء

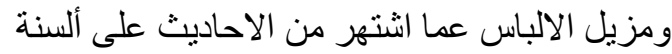

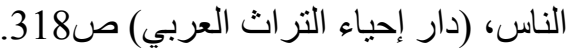

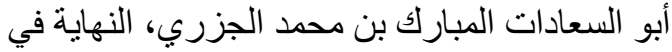

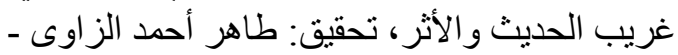
محمود محمد الطناحي (بيروت: المكتبة العلمية،

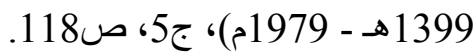
أبو الحسن علي بن إسماعيل بن سيده المرسي، المحكم و المحيط الأعظم، تحقيق: عبد الحميد هنداوي: (بيروت:

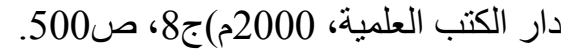
أثشار البوطي إلى المعني الاصطلاحي الثائع في تنظيم

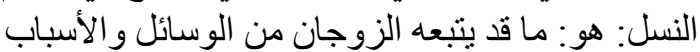

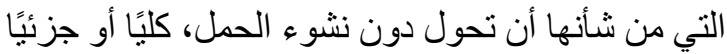

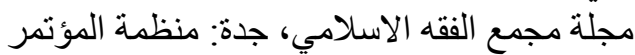

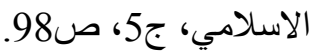

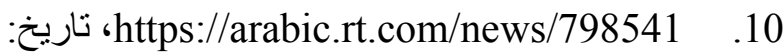
20/10/2016 هي نبنة منقرضة، كانت تتمو في شرق ليبيا، وكانت لها لانها

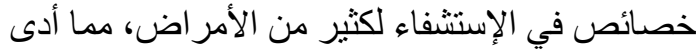

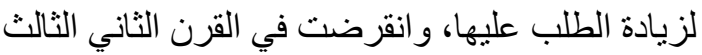
http://alarb.co/new/ قبل الميلاد. 2016-11-2 بتاريخ: detail397654.html : http://alarb.co/new/detail397654.html

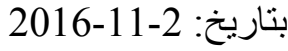

محمد الطاهر بن محمد بن محمد الطاهر بن عاشور التونسي، التحرير و التنوير المعروف بتفسير ابن عاثنور بندي

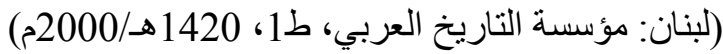
ج1، ص476 - انظر : النسائي، أحمد بن شعيب أبو عبد التران

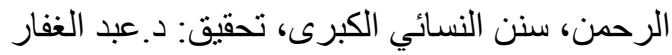

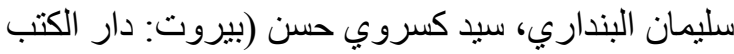

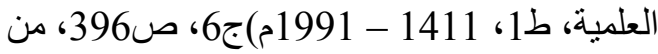
حديث ابن عباس. الطبر اني، سليمان بن أحمد بن أيوب، المعجم الكبير، الكبير،

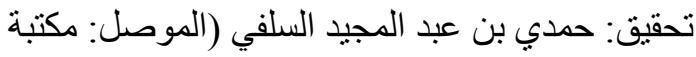
.14

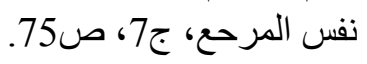




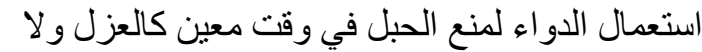
يجوز التداوي لمنع الحمل بالكلية" الفقه الإسلامي وأدلته،

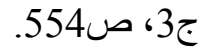

الطحاوي، أحمد بن محمد بن سلامة، مشكل الآثار للطحاوي، تحقيق: شعيب الأرناؤط (بيروت: مؤسسة

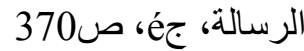

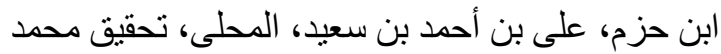

منير الدمثقي (مصر : إدارة الطباعة المنيرة، ط1، لهن

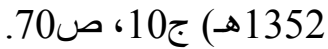

ذكر ابن القيم أن الحارث بن كلدة، نظر إلى سعد فقال:

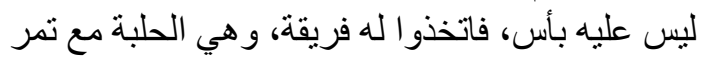

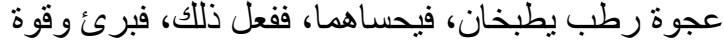

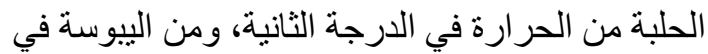

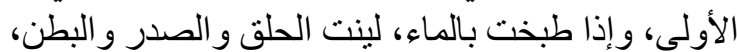

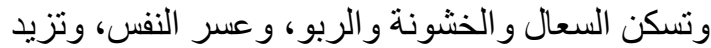

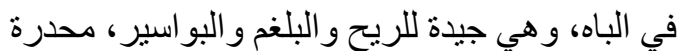

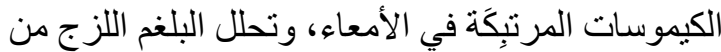

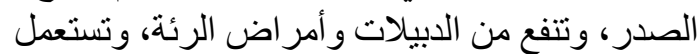

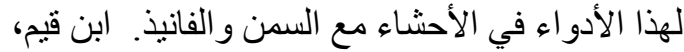

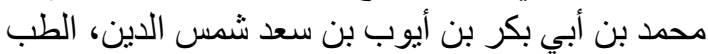

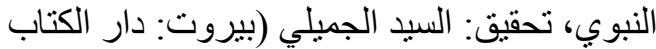

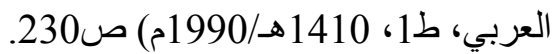

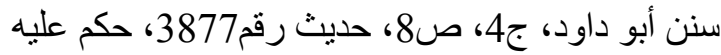

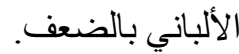

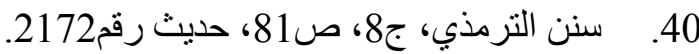
http://www.med-ethics.com . 41

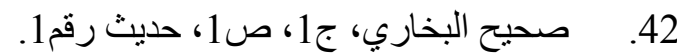

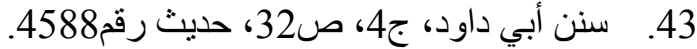

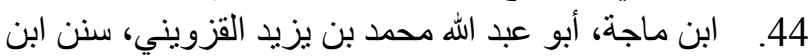

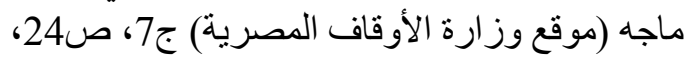
حديث رقم243.

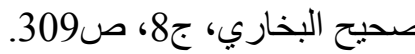

